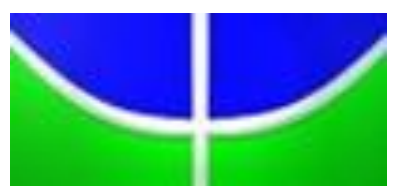

UNIVERSIDADE DE BRASÍLIA

INSTITUTO DE PSICOLOGIA

DePARTAMENTO DE Processos PsicolóGicos BÁSICOS

PROGRAMA DE Pós-GRAdUAÇÃO EM CIÊNCIAS DO COMPORTAMENTO

OS EFEITOS DE UM TREINAMENTO COGNITIVO-MOTOR NA HABILIDADE DE DIRIGIR

MICHELLE CRISTINA MATTOSO BRANDT DE ARAÚJO LIMA

Brasília, fevereiro de 2017. 
UNIVERSIDADE DE BRASÍLIA

INSTITUTO DE PSICOLOGIA

DePARTAMENTO DE Processos PsicolóGICOS BÁSICOS

PROGRAMA DE Pós-GRADUAÇÃo EM CIÊNCIAS DO COMPORTAMENTO

\section{O EFEITO DE UM PROGRAMA DE ESTIMULAÇÃO COGNITIVO-MOTORA NA HABILIDADE DE DIRIGIR EM ADULTOS JOVENS}

MICHELLE CRISTINA MATTOSO BRANDT DE ARAÚJO LIMA

Orientador: GERSON AMÉRICO JANCZURA, Ph.D

Dissertação apresentada ao Programa de PósGraduação em Ciências do Comportamento, do Departamento de Processos Psicológicos Básicos do Instituto de Psicologia, da Universidade de Brasília, como requisito parcial para a obtenção do título de mestre em Ciências do Comportamento - Área de Concentração: Cognição e Neurociências do Comportamento.

Brasília, fevereiro de 2017 
UNIVERSIDADE DE BRASÍLIA

INSTITUTO DE PSICOLOGIA

DePartamento de Processos PsicolóGicos BÁsicos

PROGRAMA DE Pós-GRAdUAÇÃo EM CIÊNCIAS DO COMPORTAMENTO

\section{BANCA EXAMINADORA}

Presidente: Gerson Américo Janczura, Ph.D

Universidade de Brasília

Membro Externo: Dra. Isabelle Patriciá Freitas Soares Chariglione Universidade Católica de Brasília

Membro Interno: Dra. Goiara de Mendonça Castilho Universidade de Brasília

Membro Suplente: Dr. Luciano G. Buratto

Universidade de Brasília 


\section{Agradecimentos}

Ao Professor Gerson Américo Janczura, não apenas por sua orientação, mas principalmente pelo seu acolhimento e incentivo. Ao senhor o meu profundo agradecimento e admiração.

Às alunas da graduação que participaram da minha pesquisa, Ana Luíza Galvan Nuevo e Marisa Gomes Alves, pelo empenho em contribuir na coleta e análise dos dados deste trabalho.

À minha mãe, Maria da Graça. Colo para todas as horas.

Aos meus tios Cristina e Cal pelo carinho e apoio durante a minha passagem por Brasília.

Ao André Luiz, amigo e parceiro desta caminhada, pelo incentivo e por sempre acreditar no meu potencial. Muito obrigada.

Aos amigos do PPB, Flaviane Correa, Claudia Pietrobon, Ricardo Rocha, Rogério Neiva Pinheiro, Stevam Afonso e Bárbara Britto, vocês tornaram minhas aflições mais amenas. Que bom ter amigos como vocês. 
Índice

BANCA EXAMINADORA

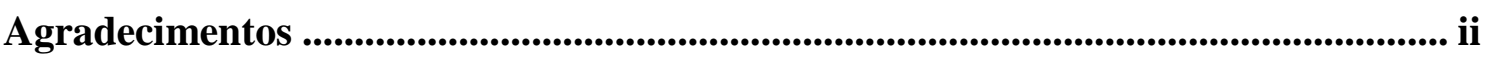

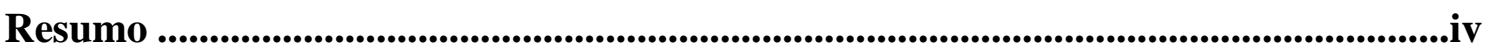

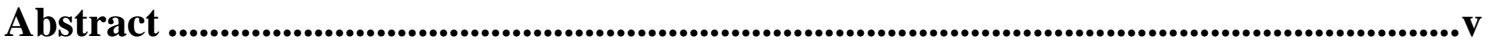

Introdução .......................................................................................................................................................6

Método ...............................................................................................................................................13

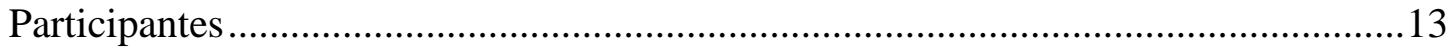

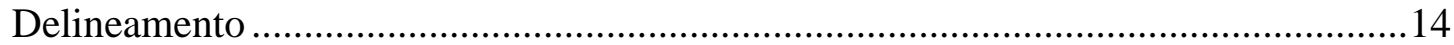

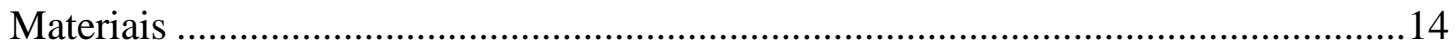

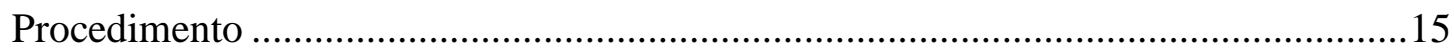

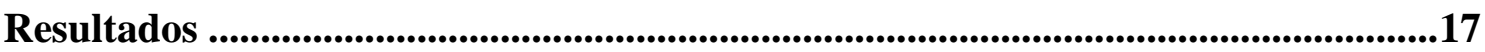

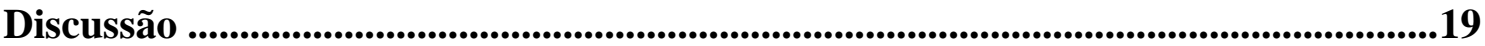

Referências .....................................................................................................................................223

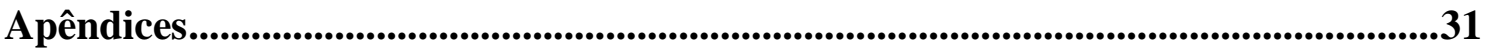




\section{Resumo}

A habilidade de dirigir envolve planejamento e ações apropriadas. As funções executivas, destacando-se atenção e memória de trabalho, são consideradas capacidades cognitivas primárias para a realização eficaz desta habilidade (Sakai, Takahara, Honjo, Doi, Sadato, \& Uchiyama, 2012). Este estudo analisa a eficácia de um programa de estimulação cognitivo-motora para motoristas adultos jovens, buscando aprimorar a habilidade de dirigir. O programa focou em atividades que estimulassem a atenção e a memória de trabalho associadas à atividades motoras. Participaram da pesquisa 22 indivíduos(20 mulheres e 2 homens) com idade média de 19 anos, estudantes de graduação da Universidade de Brasília. Os participantes foram divididos em dois grupos: Grupo Experimental $(\mathrm{N}=9)$ e Grupo Controle $(\mathrm{N}=13)$. Foram realizadas comparações a fim de avaliar o efeito do programa e do momento da testagem sobre a memória de trabalho, atenção e habilidade de dirigir através de testes de atenção (Trilhas formas A e B), de memória de trabalho (teste OSPAN) e por meio da avaliação do desempenho na direção. Os resultados demonstraram efeito significativo da estimulação na memória de trabalho. Houve melhora nas medidas de atenção e prática da habilidade de dirigir antes e após a intervenção, porém não houve diferença significativa entre os grupos. Sugere-se que estudos futuros aumentem o número de sessões de estimulação, incluindo também na amostra motoristas idosos, visto que o envelhecimento acarreta declínios cognitivos nas áreas específicas analisadas nesta pesquisa e que, assim, poderiam se beneficiar deste programa.

Palavras-chave: atenção, memória de trabalho, estimulação cognitivo-motora, habilidade de dirigir. 


\begin{abstract}
The drive ability involves planning and appropriate actions. Executive functions, especially attention and working memory, are considered primary cognitive capacities for the effective performance of this ability (Sakai, Takahara, Honjo, Doi, Sadato, \& Uchiyama, 2012). This study analyzes the effectiveness of cognitive-motor stimulation for young adult drivers, in order to improve their performance of driving ability. The focused on activities that stimulated attention and work memory associated with motor activities. Participated in the study 22 subjects ( 20 women, 2 men) with a mean age of 19 years, graduate students of the Universidade de Brasília ). Participants were divided into two groups: Experimental Group $(\mathrm{N}=9)$ and Control Group $(\mathrm{N}=13)$.

Comparisons were made to evaluate the effect of stimulation program and testing moment on work memory, attention and drive ability though attention tests (Tracks forms A and B), working memory (OSPAN Test) and by assessing performance in drive ability. The results demonstrated a significant effect of stimulation program in working memory. There was an improvement in attention and performance of driving ability measures after the intervention, but there was no significant difference between control and experimental groups. It is suggested that future studies increase the number of stimulation sessions and sample size, including older drivers. Aging brings cognitive declines in the specific areas analyzed in this study and, therefore, these drivers could be benefited by this program.
\end{abstract}

Keywords: attention, work memory, cognitive-motor stimulation, driving ability. 
A habilidade de dirigir é um processo complexo que envolve planejamento e ações apropriadas. As funções executivas, destacando-se a atenção e memória de trabalho, são consideradas capacidades cognitivas primárias para a realização eficaz desta habilidade (Fort et al, 2010; Anstey, Horswill, Wood, \& Hatherly, 2012; Asimacopulos, Boychuck, Sondegaard, Poulin, Ménard, Korner-Bitensky, 2012; Sakai et al., 2012; Werneke, \&Vollrath, 2012; Garrison \& Willians, 2013).

Estudos sobre o tema demonstram que uma das maneiras para se adquirir uma habilidade, é associar conhecimentos teóricos a repetidas práticas. A repetição constante de uma tarefa nos habilitaria a executá-la, promovendo a especialização na respectiva área (Anderson, 2004).

Chama-se cognição motora a habilidade de planejarmos e executarmos um movimento (Smith \& Kosslyn, 2008). Esta articulação entre planejar e executar referese à capacidade do indivíduo de utilizar estratégias para resolver problemas. A cognição motora, neste sentido, abrange processos mentais complexos como: planejamento, preparação e produção de ações apropriadas. Segundo os autores, a chave para a compreensão da natureza da cognição motora é o ciclo percepção-ação, ou seja, a transformação da percepção de um padrão perceptivo em padrões de movimentos coordenados.

Evidências neuropsicológicas e comportamentais sugerem que o link mediador da percepção e ação é a representação mental, um código compartilhado no cérebro que contém tanto percepções quanto ações. Desta forma, a representação mental de uma sequência de movimentos necessárias para a realização de uma determinada ação viabiliza uma performance mais rápida e eficiente (Smith \& Kosslyn, 2008).

Estas condições são observadas na aquisição da habilidade de dirigir automóveis, que inclui o conhecimento declarativo sobre o ato de dirigir associado a exercícios práticos de direção. Anderson (2004) descreve três estágios relacionados ao desenvolvimento e aquisição de uma habilidade: estágio cognitivo, estágio associativo e estágio autônomo, respectivamente.

No estágio cognitivo os sujeitos desenvolveriam uma codificação declarativa da habilidade, registrando na memória um conjunto de fatos relevantes para o desempenho posterior. Esta etapa corresponderia às aulas teóricas dos cursos de habilitação de motoristas. No estágio associativo ocorreria uma redução dos erros de compreensão inicial e início da prática de um procedimento bem-sucedido para a execução da 
habilidade. Neste momento, porém, o procedimento associado à tarefa ainda não está automatizado e o indivíduo necessita do conhecimento declarativo aprendido nas aulas teóricas para orientar o seu desempenho nas aulas práticas. No último estágio, o procedimento se torna automático e mais rápido, exigindo poucos recursos da atenção.

Estudos envolvendo processos cognitivos e habilidade de dirigir focam, em sua maioria, nas questões relacionadas ao envelhecimento e às perdas cognitivas relacionadas ao avançar da idade.(Adrian, Postal, Moessinger, Rascle, \& Charles, 2011; Fafanova, \&Vollrath, 2011;Wild-Wall, Hahn, \& Falkenstein, 2011;Leversen, Hopkins, \& Sigmundsson, 2013; Casutt, Martin, Keller, \& Jancke, 2014; Perumparaichallai, Husk, Myles, \&Klonoff, 2014). Poucas são as pesquisas sobre este tema envolvendo adultos jovens (Boccara, Delhomme, Vigal, Gomel, \& Rogaslki, 2011; Lenné, Liu, Salmon, Holden, \& Moss, 2011;Yamani, Samuel, Knodler, \& Fisher, 2016.

A memória de trabalho e a atenção relacionada ao envelhecimento e à habilidade de dirigir tem sido de grande interesse público em função da necessidade de se buscar estratégias para a manutenção da habilidade de dirigir ao longo da vida ou da existência de patologias mais típicas no processo de envelhecimento, particularmente as demências (Brookhuis \&Waard, 2010; Klonoff et al, 2010, Anstey\& Wood, 2011; Andrews \& Wersterman, 2012; Bunce, Young, Blane, \& Khugputh, 2012; Devlin, McGillivraya, Charlton, Lowndes, \& Etienne, 2012; Reimer, Mehler, Wang, \& Coughlin, 2012; Stinchcombe \& Gagnon, 2013; Pierce \& Andersen, 2014; Verster, Bervoets, Klerk, \& Roth, 2014). Algumas questões levantadas nestas pesquisas referem-se à investigação da existência de diferenças significativas na performance de direção associadas a mudanças cognitivas. A conclusão destes estudos aponta que alterações cognitivas ao longo da vida podem afetar a habilidade da pessoa dirigir com segurança e eficácia e que os fatores mais comprometedores para uma habilidade de dirigir estão relacionados à capacidade atencional (atenção dividida) e à memória de trabalho. Resultados semelhantes foram observados com motoristas adolescentes. Problemas referentes a uma direção insegura nesta faixa etária também estão relacionados à memória de trabalho e capacidade atencional, em função de imaturidade cerebral e falta de experiência prática (Romer, Lee, McDonald, \& Winston, 2013).

Medidas neuropsicológicas, principalmente de memória de trabalho e atenção, foram utilizadas em estudos sobre avaliação do potencial de direção segura de 
motoristas e seus resultados foram correlacionados com a habilidade de dirigir. Testes como o UFOV (Visual Awareness Research Group, 2014), o teste de Trilhas formas A e B (Reitan RM, 1958) e o Operation Span Task (Unsworth, Heitz, Schrock,\& Engle, 2005) parecem ser bons preditores da correlação entre declínio cognitivo e habilidade de dirigir em motoristas idosos ou pacientes com demência (Cassavaugh \& Kramer, 2009; Silva, Laks, \& Engelhardt, 2009; Henderson et al., 2010; Ishimatsu, Miura, \& Shinohara, 2010; Anstey \& Wood, 2011, Ott et al., 2013).

Estudos sobre a aquisição da habilidade de dirigir e sua consolidação em motoristas novatos visam buscar estratégias que maximizem o aprendizado, a fim de formar motoristas que executem uma direção segura (Charlton \& Starkey, 2011; Isler, Sterkey, \& Sheppard, 2011; Huang \& Ford, 2012). O estudo de Charlton e Starkey (2011) investigou o efeito da prática e da automatização na atenção na habilidade de direção. Usando um simulador, os participantes dirigiram e num cenário de estrada por 12 semanas. Os resultados evidenciaram o desenvolvimento de melhores padrões de direção e melhor performance na detecção de objetos, indicando que houve uma proceduralização da habilidade de dirigir. A variabilidade da velocidade e a mudança de posição na pista diminuíram significativamente em função da prática no simulador. Os resultados foram mais significativos nos estágios finais do experimento. A pesquisa foi feita com dois grupos constituídos por pessoas com idade variando entre 20 e 50 anos e relato de hábito de dirigir semelhantes. O grupo denominado Expert foi constituído por pessoas que relataram ter, em média, 15 anos de experiência de direção, e que dirigiam entre $10 \mathrm{~km}$ e $900 \mathrm{~km}$ por semana, enquanto que o grupo denominado Casual, relataram ter, em média, 8 anos de experiência de direção, e que dirigiam semanalmente entre $20 \mathrm{~km}$ e $500 \mathrm{~km}$. O grupo Expert treinou duas vezes por semana durante 12 semanas no simulador, enquanto que o Casual participou de uma única sessão. O resultado da pesquisa apontou que o uso do simulador pode ser útil para a automatização da habilidade de dirigir, mostrando significativa melhora de performance e automatização no grupo Expert em relação ao Casual.

Huang e Ford (2012) investigaram o impacto do treinamento da direção defensiva associado ao feedback de um observador, com o objetivo de identificar se este tipo de intervenção melhoraria o controle focal, a crença sobre a capacidade de prevenir acidentes e o impacto no comportamento de dirigir. O estudo aplicou um treinamento de cinco semanas no qual 112 indivíduos foram avaliados quanto ao controle focal e o 
comportamento de direção em dois momentos (antes e depois da intervenção). O treinamento foi direcionado a questões sobre consciência situacional, a inter-relação entre tarefas de direção e o comportamento do motorista, os controles de direção e velocidade. O treinamento incluiu grupos de discussão, pequenos textos e vídeos. Paralelamente a isto, os motoristas realizavam um percurso de direção e recebiam feedback de um observador enquanto realizavam a atividade (percorrer determinados caminhos). Foi observado que o foco do controle da direção pode ser influenciado pelo treinamento e pelo feedback do observador, e que mudanças no foco do controle da direção pode predizer mudanças na habilidade de dirigir.

Isler et al. (2011) estudaram os efeitos de dois treinamentos. O treinamento de "habilidades das funções superiores" (que incluía: consciência situacional, busca visual, padrão antecipatório, gerenciamento de risco e auto avaliação da performance de direção) e o treinamento de "manejo da direção" (que correspondia ao treino tradicional, ou seja, instrutores forneciam orientações e feedback sobre manobras entre cones, posicionamento nas faixas, freada, performance nas curvas e estacionamento em paralelo).O objetivo foi verificar o impacto do tipo de treinamento na performance de direção, na percepção de risco, na percepção de direção arriscada e no nível de confiança de motoristas jovens e inexperientes. Além das duas condições acima, o estudo ainda contou com um Grupo Controle no qual os participantes se envolveram em atividades não relacionadas à direção como atividade de turismo, esportes e socialização. Os resultados evidenciaram que os participantes do grupo "funções superiores" apresentaram significativa melhora em relação ao grupo "manejo da direção" nos seguintes itens: busca visual, percepção de padrão, atitudes seguras de distância entre os veículos e perigos de ultrapassagem. Os resultados positivos do grupo "manejo da direção" se relacionaram ao controle da direção, mudanças na velocidade e em escores de direção como um todo. No entanto, este grupo não obteve ganhos no padrão de percepção, na consciência das atitudes de risco na direção e na confiança do motorista. O estudo apontou a necessidade da ampliação do treinamento tradicional da direção incluindo aspectos como direção segura, rapidez cognitiva, percepção e atitudes diante de fatores de risco na direção.

Se a desatenção e sobrecarga na memória de trabalho (acúmulo de tarefas realizadas concomitantemente) estão fortemente associadas à performance empobrecida da habilidade de dirigir em motoristas novatos (Recarte \& Nunes, 2003; Ross, Jongen, 
Wang, Brijs, \& Brijs, 2013), pensar em atividades que estimulem essas duas funções parece ser uma alternativa promissora no aprimoramento da performance de direção.

As intervenções cognitivas surgiram a partir dos achados das neurociências sobre plasticidade cerebral associada aos conhecimentos da psicologia cognitiva, da neuropsicologia e da neurologia e que tem como objetivo desenvolver técnicas e estratégias que possibilitem uma melhora em áreas cognitivas específicas como, por exemplo, a atenção, a memória e as funções executivas (Dahlin, Nyberg, Backman, \& Neely, 2008; Smith et al,2009; Jaeggi, Buschkuehl, Jonides, \& Shah, 2011; Barulli, \& Stern, 2013; Redick et al, 2013).

Existem várias técnicas de intervenção cognitiva, entre elas destacam-se a estimulação cognitiva e o treinamento cognitivo. Muitas vezes, estes termos são usados como sinônimos, mas cada um deles reserva uma particularidade. A estimulação cognitiva busca uma melhora funcional por meio da repetição de determinadas atividades, já o treinamento cognitivo visa melhorar o desempenho de uma tarefa e/ou função cognitiva por meio do ensino de estratégias (Chariglione \& Janczura, 2013).

A noção de plasticidade cerebral e, consequentemente, da possibilidade de aprimorar habilidades cognitivas e motoras ao longo da vida, tem levado vários pesquisadores a buscar desenvolver diferentes intervenções cognitvas para melhorar a habilidade de dirigir (Edwards et al., 2009;Soliman \& Mathna, 2009; Marmeleira, Godinho,\& Fernandes, 2009; Marmeleira, Godinho, Tlemcani, \& Fernandes, 2011;Ross et al., 2015). Estudos demonstram resultados contraditórios sobre este tema. Bealand, Goode, Salmon \& Lenné (2013) fizeram uma revisão de literatura sobre programas de treinamentos de direção e sua eficácia, incluindo tanto aqueles realizados antes da obtenção da licença de motorista quanto os realizados para melhorar a habilidade de dirigir após obtenção da licença. A revisão indicou que alguns treinamentos cognitivos são eficazes para a aquisição de habilidade procedural e que outros programas têm apresentado melhora no padrão perceptivo. $\mathrm{O}$ estudo apontou que o treinamento convencional realizado em autoescola não reduz o risco de acidentes em jovens e que treinamentos de funções superiores, como padrão perceptivo, pode ser uma alternativa. Treinamento de Resiliência e de Insight (reduzir os riscos de comportamentos inadequados através do ensino das aptidões interpessoais necessárias para uma direção 
segura e autoavaliação realística de suas habilidades) parece reduzir o excesso de confiança entre os jovens, viabilizando uma direção mais segura.

Uma questão importante que tem sido discutida é se o aprendizado promovido por intervenções cognitivas podem ser transferidos para a atividade da vida real (validade ecológica). O que se tem verificado é que nem toda intervenção cognitiva promove a transferência de conhecimento adquirido para a condição real de dirigir (Gaspar, Neider, Simons, McCarley, \& Kramer, 2013). Este tem sido um desafio a ser superado pelos pesquisadores da área. Muitas pesquisas utilizaram simuladores como forma de favorecer a transferência do aprendizado(Sonet al, 2009; Shanmugaratnam, Kass, \& Arruda, J. E, 2010; Andersen, Ni, Bian, \& Kang, 2011; Jacson, Croft, Kennedy, Owens, \& Howard, 2013).Por se tratar de uma habilidade motora, o simulador criaria um ambiente promissor nesta investigação científica. Até o momento, esta parece ser a ferramenta mais eficaz na transferência do aprendizado motor adquirido para a vida real.

Este estudo propõe um programa de estimulação cognitivo-motora para motoristas adultos jovens, vizando a melhora da habilidade de dirigir.O programa teve como foco a atenção e a memória de trabalho associados à atividades motoras. Para tal, baseou-se no estudo de Marmeleira et al. (2009) e Marmeleira, Godinho et al. (2011) que se utilizaram de um programa de estimulação cognitiva associado à prática de exercícios físicos com intuito de aprimorar a velocidade no comportamento de motoristas idosos.

Pesquisas evidenciam que exercícios e atividades físicas têm impactos importantes em parâmetros psicológicos (Chodzko-Zajko \& Moore, 1994), principalmente em relação a uma melhora na velocidade do processamento de informação (Marmeleira et al., 2009; Marmeleira et al., 2011), na capacidade atencional em situações que demandam atenção dividida (Hawkins, Kramer,\& Capaldi, 1992) e na melhora da atenção visual (Roth, Goode, Clay,\& Ball, 2003). Sabe-se que estes elementos psicológicos têm relação positiva com a performance de direção segura (Cassavaugh\& Kramer, 2009; Silva, Laks, \& Engelhardt, 2009; Ishimatsu et al., 2010; Henderson et al., 2010; Anstey \& Wood, 2011; Ott et al., 2013).

Investigações também evidenciaram que a atividade física está associada a mudanças em mecanismos subjacentes como fluxo cerebral do sangue (Swainet al., 2003), estrutura cerebral (Colcombe et al., 2006) e neurotransmissores (Meeusen, 2005). Entretanto, poucas investigações têm explorado o potencial entre o treino físico e 
a habilidade de dirigir (Hancock, Kane, Scallen \& Albinson, 2002; Marmaleira et al., 2009 e 2011). Estudos recentes apontam que determinadas formas de exercícios que requerem processamento de informação e onde a velocidade no comportamento é crucial para a realização da atividade, podem ser positivamente transferidas para situações do dirigir (Marmeleira et al., 2009; Matos \& Godinho, 2009). No entanto, Hancock et al. (2002) não encontraram nenhuma vantagem da prática de atividades físicas em experimentos com motoristas.

Uma questão importante diz respeito a qual tipo de exercício é mais eficaz no melhoramento da habilidade de dirigir. É razoável assumir que atividades que envolvam o aprimoramento da velocidade do comportamento possam ter impacto na capacidade do indivíduo em responder rapidamente aos estímulos do meio ambiente enquanto dirigem. Esta ideia é embasada na hipótese de que, para que ocorra a transferência dos benefícios das intervenções cognitivas para uma situação real, estes devem envolver demandas semelhantes de processamento cognitivo (Magill, 2003). Além disso, estudos que analisaram o efeito combinado de exercícios físicos e mentais reportaram maiores benefícios cognitivos quando comparados a tarefas de exercícios físicos e mentais realizadas de forma individual (Oswald, Rupprecht, Gunzelmann, \&Tritt, 1996; Fabre, Chamari, Mucci, Masse-Biron, \& Prefaut, 2002).

As considerações acima levaram ao desenvolvimento de um programa de estimulação cognitivo-motora que contemplasse atividades físicas de natureza perceptomotora, exercícios atencionais e de memória de trabalho a fim de promover um incremento nestas funções cognitivas e na habilidade de dirigir de motoristas jovens. A expectativa do estudo previu um efeito positivo de diferentes atividades cognitivas e motoras no incremento da atenção, memória de trabalho e, consequentemente, na performance da habilidade de dirigir. 


\section{Método}

Participantes. Foram selecionadas 30 pessoas, maiores de 18 anos, que possuíam carteira de habilitação da categoria B. Todos os participantes eram alunos da graduação da Universidade de Brasília (UNB) e foram selecionados por conveniência, por meio de convite realizado nas dependências da instituição. O critério de inclusão foi a posse da carteira de habilitação. As pessoas que se interessaram em participar da pesquisa, de forma voluntária e não remunerada e foram convidadas a assinar o Termo de Consentimento Livre e Esclarecido (Apêndice A). Esta pesquisa foi aprovada pelo CEP/CONEP (Plataforma Brasil/Ministério da Saúde) sob o número CAAE: 60893816.8.0000.5540.

Os participantes realizaram as seguintes etapas: inscrição, avaliação préintervenção, intervenção, avaliação pós-intervenção.

A Figura 1 descreve o número de participantes iniciais e a perda amostral ocorrida em cada etapa da pesquisa.

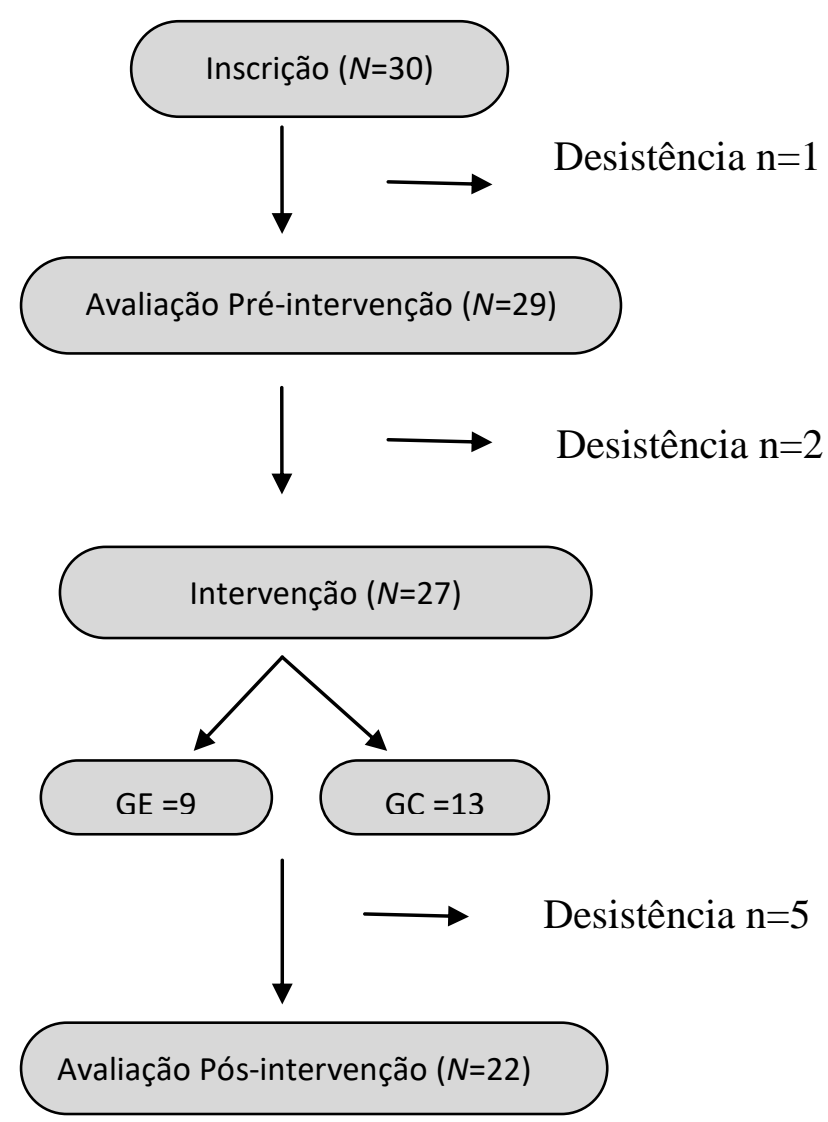

Figura 1. Processo de alocação dos participantes. 
Os participantes foram alocados em dois grupos. O Grupo Experimental (GE) foi formado, inicialmente, por 13 mulheres e 2 homens, com média de idade de 19 anos e tempo médio de habilitação de 11 meses. Ao final do programa este grupo contou com 8 mulheres e 1 homem. A média da frequência semanal de dirigir deste grupo foi de 3 dias por semana. O Grupo Controle (GC) contava, inicialmente, com 14 mulheres e 1homem, com média de idade de 19 anos e tempo médio de habilitação de 15 meses. Ao término do programa o grupo contou com 12 mulheres e 1 homem. A média da frequência semanal de dirigir deste grupo foi de quatro dias por semana.

Delineamento. Aplicou-se um delineamento experimental com avaliações pré e pós-intervenção. Foram realizadas comparações a fim de avaliar o efeito do tipo de condição (com versus sem estimulação cognitiva) manipulada entre-sujeitos, e o momento da testagem (antes e depois) manipulado intra-sujeitos, perfazendo um delineamento fatorial misto $2 \times 2$. As variáveis dependentes foram memória de trabalho, atenção e habilidade de dirigir. A alocação dos participantes aos níveis do fator tipo de condição foi aleatória.

Materiais. Os materiais foram organizados em três categorias: (a) avaliação cognitiva da atenção e da memória incluindo os testes Operation Span Task - OSPAN (Unsworth, Heitz, Schrock, \& Engle, 2005), Teste de Trilhas formas A e B (Reitan, 1958) e Digit Span (ordem direta e indireta); (b) questionário de avaliação da prática de dirigir com 23 itens, baseado nos itens avaliados na prova prática do Detran (Departamento Estadual de Trânsito) (Apêndice B), e (c) materiais referentes ao programa de estimulação cognitivo-motora, descritos abaixo:

Materiais do Programa de Estimulação Cognitivo-Motora.Todas as sessões do programa de estimulação cognitivo-motora utilizaram computador, Datashow, cadeiras, lápis, canetas, borrachas e folhas branca papel A4 para anotações.Os materiais específicos utilizados em cada sessão foram os seguintes:

- Sessão 1: 20 balões na cor azul. Gravação de áudio de sons ambientais de uma rua com tráfego com duração de 30 segundos, 45 segundos e 60 segundos.

- Sessões 2 e 9: um apito.

- Sessões3 e 4: 10 balões na cor branca e 10 balões na cor roxa. Gravação de áudio de sons ambientais de tráfego com duração de 5 segundos, 15 segundos, 20 segundos, 25 segundos, 45 segundos e 4 
pistas sonoras (som de buzina de carro, som de buzina de caminhão, som de sirene de ambulância, som de freada) com tempo de duração entre 3 e 5 segundos.

- Sessão 5: 17 folhas de papel A4 para cada participante contendo diversos números espalhados aleatoriamente pela folha, digitadas em fonte Times New Roman, tamanho 12. As sequências numéricas foram as seguintes: de 1 a 15, de 1 a 30, 1 a 45, de 1 a 60, de 1 a 75 e 1 a 90.Houve duas variações de posição espacial dos números para cada sequência. A sequência de 1 a 5 foi feita com apenas uma posição espacial.

- Sessões 6 e 8: 1 rolo de fita crepe, gravação de áudio de sons ambientais de uma rua com tráfego com duração de 30 segundos, 45 segundos e 1 minuto, gravação de áudio com sons específicos relativos ao trânsito (buzina de caminhão, buzina de carro, freada, sirene de polícia, sirene de ambulância) com apresentação de aproximadamente 5 segundos e um semáforo com $90 \mathrm{~cm}$ de altura e $35 \mathrm{~cm}$ de largura contendo três luzes nas cores verde, amarelo e vermelho.

- Sessão 7: 17 folhas de papel A4 com diversos números e letras espalhadas aleatoriamente pela folha, digitadas na fonte Times New Roman tamanho 12. A posição espacial dos números e letras na folha foi alocada aleatoriamente. Para uma mesma sequência alfa-numérica houve duas variações na ordem da posição espacial dos elementos na folha. As sequências alfa-numéricas foram as seguintes: De 1 a 3 e $\mathrm{A}$ aC, de 1 a 5 e A a E, de 1 a 10 e A a J, de 1 a 15 e A a O, de 1 a 20 e A a T e de 1 a 26 e A a Z.

Procedimentos. Os procedimentos foram administrados em três etapas: préintervenção, intervenção e pós-intervenção, descritos a seguir.

Pré-intervenção: incluiu a, avaliação do desempenho da memória de trabalho e da atenção e avaliação prática de direção. Esta última foi realizada por um instrutor de uma autoescola, em carro da própria empresa (marca Gol, ano 2014, com direção hidráulica). A avaliação foi realizada por um percurso de 15 minutos nas redondezas da universidade. Todos os participantes realizaram o mesmo percurso. Durante a avaliação encontravam-se no carro o participante, o instrutor e a pesquisadora. Os testes 
neuropsicológicos (memória de trabalho e atenção) foram aplicados individualmente em uma sessão com duração de, aproximadamente, 40 minutos em até 15 dias antes do início da intervenção. O teste de Trilhas (formas A e B) foi aplicado de forma escrita tendo como tarefa ligar vários números (forma $\mathrm{A}$ ) ou ligar números a letras (forma $\mathrm{B}$ ) seguindo uma ordem crescente e sem tirar o lápis do papel. As respostas foram marcadas pelo próprio participante na folha do teste. O tempo de aplicação do teste foi de até 5 minutos para cada forma. O teste OSPAN foi realizado no computador sendo a tarefa do sujeito julgar a correção dos resultados de operações aritméticas simples e memorizar uma sequência de palavras. A aplicação do OSPAN durou, aproximadamente, 20 minutos. O resultado do desempenho do participante foi marcado pelo pesquisador em uma folha de respostas. O teste Digit Span consistiu da apresentação de uma série de números (sequência de até nove dígitos na ordem direta e até oito dígitos na ordem inversa) onde o participante deveria responder de duas formas: na forma direta, a tarefa foi repetir em voz alta os números na ordem em que foram apresentados pelo pesquisador. No segundo momento, o participante deveria repetir na ordem inversa os números verbalizados pelo pesquisador. Em ambas as condições o participante deveria responder tão logo o pesquisador terminasse de falar a série de números. O tempo de aplicação do teste foi de, aproximadamente, 5 minutos.

Intervenção: consistiu da administração de um programa de estimulação cognitiva. O programa baseou-se no estudo de Marmeleira, Godinho e Fernandes (2009) e contemplou os temas controle atencional, controle motor e memória de trabalho que foram desenvolvidos em nove sessões, com duração de 45 minutos cada. As sessões foram administradas em cinco datas: quatro com duas sessões e uma contendo uma sessão totalizando duas semanas. Cada encontro durou 90 minutos incluindo10 minutos de intervalo entre sessões. No caso do encontro de sessão única, o tempo foi de 60 minutos (sessão 3). Cada sessão incluiu dois tipos de atividades: Psicoeducação e Exercícios Práticos. A Psicoeducação (Atividade 1) tinha por objetivo educar os participantes sobre os conceitos de determinadas funções cognitivas e sua importância para uma boa performance de direção. A atividade foi implementada através de aulas expositivas auxiliadas por Datashow e discussão dos conceitos e estratégias de intervenção relacionadas à habilidade de dirigir. Os participantes dispunham de papel e caneta para anotações. Esta atividade teve duração de 10 minutos, com exceção da sessão 1 que durou 20 minutos.Os Exercícios Práticos (Atividade 2) tiveram por 
objetivo a aquisição de habilidades e recursos para uma melhor performance da função cognitiva associada a habilidade de dirigir. Foram executadas atividades de natureza motora e perceptual associadas às respectivas funções cognitivas que tiveram a duração de 30 minutos. As atividades envolviam tarefas como: 1) sustentar balões no ar rebatendo e executar ações apropriadas de acordo com pistas sonoras apresentadas. 2) realizar exercícios de imagética coordenando conhecimento declarativo da habilidade de dirigir à realização de movimentos corporais. 3) Realizar percurso, dentro de uma sala de treinamento, caminhando entre faixas que simulavam faixas de trânsito e executando ações específicas de acordo com a apresentação de pistas. As pistas utilizadas para as atividades foram sonoras (sons de: freada, buzina de caminhão, buzina de carro, sirene) e visuais (utilização de um semáforo contendo as três cores de sinalização de trânsito (verde, amarelo e vermelho). A aplicação do programa de estimulação cognitivomotora seguiu uma ordem crescente de dificuldade da tarefa e buscou o encadeamento das sessões, afim de favorecer e fixar o aprendizado.O detalhamento de cada sessão do programa de estimulação cognitivo-motora pode ser observado no Apêndice D.

Pós-intervenção: correspondeu à avaliação do desempenho da memória de trabalho, atenção e conhecimentos práticos sobre habilidade de dirigir aplicada em até 15 dias após a conclusão da intervenção. Os procedimentos desta etapa foram idênticos à etapa pré-intervenção. Os grupos controle e experimental foram submetidos a esta etapa no mesmo período.

\section{Resultados}

Os dados foram analisados através de Análises de Variância mistas, adotando-se o nível de significância de 5\% ( $p<0,05)$. Os efeitos do programa de estimulação cognitivo-motora foram avaliados comparando-se o desempenho dos grupos experimental e controle nas medidas de tempo de resposta e acertos nos testes Trilhas A (atenção focada), Trilhas B (atenção dividida), Digit Span Ordem Direta (memória de curto prazo), Digit Span Ordem Inversa e OSPAN (memória de trabalho) antes e após a intervenção. No teste Trilhas, o desempenho superior está associado ao tempo menor de execução da tarefa enquanto que no Digit Span e no OSPAN a produção de mais acertos indica melhor desempenho. Na avaliação da prática de dirigir é quantificado o número de erros cometidos pelo motorista (máximo de erros $=23$ ), assim, quanto menor o número de erros melhor é a habilidade de dirigir. 
Não foi significativa a diferença entre os grupos controle e experimental no teste Trilhas A, entretanto, observou-se uma diminuição significativa no tempo de resposta para a execução do teste $[\mathrm{F}(1,20)=12,77, \mathrm{p}=0,00, d=0,78]$, sendo a média de tempo em segundos apresentada após o a intervenção $(\mathrm{M}=26,16, \mathrm{DP}=6)$ significativamente inferior à apresentada antes da intervenção $(\mathrm{M}=32,22$; $\mathrm{DP}=9,49)$. Este efeito foi semelhante ao Trilhas B no qual a única diferença significativa foi na redução do tempo de execução $[(\mathrm{F}(1,20)=15,56, \mathrm{p}=0,00, d=0,79)$ sendo a média do tempo em segundos antes da intervenção igual a 72,20 (DP = 28,85) e após igual a 52,24 (DP = 16,71).

A média de palavras lembradas no OSPAN foi significativamente maior para os participantes do grupo experimental $(M=42,11, \mathrm{DP}=7,18)$ do que para o grupo controle $(\mathrm{M}=36,42, \mathrm{DP}=5,82), \mathrm{F}(1,20)=5,11, \mathrm{p}=0,03, d=0,88$. Também foi significativa a diferença entre as médias antes e após a intervenção, $\mathrm{F}(1,20)=14,44$, p $=0,00, d=0,57$, sendo a média pré-intervenção $=37,34(\mathrm{DP}=6,85)$ e pós-intervenção $=$ $41,19(\mathrm{DP}=6,63)$.

A média de palavras lembradas na posição correta no OSPAN foi significativamente superior para os participantes do grupo experimental $(M=32,89$, DP $=10,22)$ do que para o grupo controle $(\mathrm{M}=22,61, \mathrm{DP}=9,70), \mathrm{F}(1,20)=7,25, \mathrm{p}=$ $0,01, d=1,03$. Também foi significativa a diferença entre as médias gerais antes e após a intervenção, $\mathrm{F}(1,20)=17,21, \mathrm{p}=0,00, d=0,63$, sendo a média pré-intervenção $=$ 24,40 (DP = 10,21) e pós-intervenção = 31,10 ( $\mathrm{DP}=11,11)$.

Os participantes do grupo experimental produziram uma média de conjuntos de palavras lembrados corretamente no OSPAN significativamente maior $(\mathrm{M}=6,55, \mathrm{DP}=$ $2,38)$ do o grupo controle $(\mathrm{M}=4,73, \mathrm{DP}=2,05), \mathrm{F}(1,20)=4,53, \mathrm{p}=0,04), d=0,82$. Também foi significativa a diferença entre as médias antes e após a intervenção, F (1, $20)=20,20, \mathrm{p}=0,00, d=0,65$, sendo a média pré-intervenção $=4,91(\mathrm{DP}=2,11)$ e pósintervenção=6,38 (DP =2,40). Este resultado foi semelhante à média do número de palavras lembradas dos conjuntos corretos no OSPAN $[\mathrm{F}(1,20)=4,93, \mathrm{p}=0,03, d=$ $0,76]$ sendo que os participantes do grupo experimental lembraram mais palavras $(\mathrm{M}=$ $19,05, \mathrm{DP}=8,63)$ do que o grupo controle $(\mathrm{M}=12,50, \mathrm{DP}=8,63)$. Diferença estatisticamente significativa também foi observada entre as médias pré e pósintervenção, $\mathrm{F}(1,20)=25,30, \mathrm{p}=0,00, d=0,70$, sendo a média pré-intervenção $=13,03$ $(\mathrm{DP}=6,77)$ e pós-intervenção $=18,52(\mathrm{DP}=8,82)$. 
Não foi significativa a diferença entre os grupos controle e experimental na avaliação prática, no entanto, observou-se uma diminuição significativa dos erros da prática em ambos os grupos $[\mathrm{F}(1,20)=12,54, \mathrm{p}=0,00, d=0,50]$, sendo a média de erros apresentada após a intervenção $(\mathrm{M}=3,39, \mathrm{DP}=2,10)$ estatisticamente inferior à apresentada antes da intervenção $(\mathrm{M}=4,49 ; \mathrm{DP}=2,30)$.

Não foram encontradas diferenças significativas entre os grupos nos testes Digit Span Ordem Direta e Ordem Inversa.

\section{Discussão}

Os resultados obtidos nessa pesquisa indicaram o efeito de diferentes intervenções cognitivas, particularmente relacionadas à atenção, memória de trabalho e controle motor, envolvidas na habilidade de dirigir. Esta influência foi observada contrastando o desempenho entre dois grupos. O grupo experimental recebeu um programa de estimulação cognitivo-motora desenvolvido em nove sessões que incluíram atividades de atenção, memória de trabalho e controle motor. Cada sessão foi desenvolvida em dois momentos: o primeiro teve por objetivo discutir os aspectos cognitivos relacionados à habilidade de dirigir e o segundo pretendeu promover a aprendizagem através de atividades práticas. As atividades práticas incluíram exercícios motores associados a exercícios cognitivos de atenção e memória como caminhar e executar ações específicas dentro de uma sala de treinamento, utilizar de pistas auditivas e visuais, sustentar balões no ar rebatendo-os atentando para mudanças de pistas sonoras, e executar movimentos relacionados à execução de dirigir um automóvel.

As questões de pesquisa tinham como objetivo verificar o efeito de um programa de estimulação cognitivo-motora na habilidade de dirigir de motoristas adultos jovens. A hipótese defendida buscava corroborar a eficácia da estimulação cognitivo-motora na melhora desta habilidade. Outro objetivo dizia respeito à estimulação cognitivo-motora favorecer a melhora na atenção e na memória de trabalho. A hipótese defendida era de que a estimulação cognitivo-motora apresentaria um resultado favorável no desempenho da atenção e da memória de trabalho.

No que diz respeito à primeira questão, o programa de estimulação cognitivomotora não apresentou ganhos significativos na habilidade de dirigir dos participantes do grupo experimental. Ambos os grupos apresentaram resultados superiores após a intervenção, não podendo concluir-se, portanto, que a estimulação tenha aprimorado a 
habilidade de dirigir dos participantes do grupo experimental. Esta avaliação levou em conta a pontuação aferida pelo questionário de desempenho realizada por um instrutor da autoescola.

Cinco fatores podem ter influenciado os resultados encontrados. O primeiro é o efeito da prática de dirigir realizado pelos participantes de ambos os grupos durante o período da pesquisa. Para se adquirir uma habilidade motora é necessário associar conhecimentos declarativos sobre a realização da tarefa à sua prática, ou seja, quanto mais praticamos, melhor adquirimos esta habilidade, desenvolvendo uma execução automatizada e eficiente (Anderson, 2004). Smith \& Kosslyn (2008) apontam uma redução no tempo de reação na realização de atividades que envolvam cognição motora a partir da capacidade, por vezes inconsciente, de antecipar a ação a ser realizada. Ou seja, uma representação de uma sequência de movimentos é planejada para depois ser executada. Quanto mais complexa a ação, maior tempo necessário para o planejamento. Quanto mais planejada e executada, menor seu tempo de reação. Sternberg (2010) faz uma análise entre pessoas mais experientes e iniciantes em diferentes domínios e aponta que as memórias armazenadas de inúmeras ações específicas realizadas favorecem a construção de esquemas, podendo assim com maior rapidez recuperar a informação e executá-la.

Como o intervalo de tempo entre as avaliações pré e pós-intervenção foi de aproximadamente um mês e os participantes do grupo controle relataram apresentar o hábito de dirigir em média de quatro vezes por semana, o efeito da prática durante este período pode ter influenciado os resultados. O segundo fator foi o número de sessões reduzidas do programa (nove sessões, realizadas em cinco dias). O número de sessões realizadas nas pesquisas de referência para o presente trabalho variava entre oito e doze semanas, aplicadas três vezes por semana (Marmaleira et al., 2009 e 2011). Ou seja, é razoável assumir que o número de sessões assim como o período no qual foram administradas tenha sido insuficiente para se produzir os efeitos esperados. Esta hipótese encontra sustentação em Anderson (2004) que afirma ser a repetição uma condição desejável para um aprendizado mais eficaz e duradouro. $\mathrm{O}$ terceiro fator foi a amostra utilizada no presente estudo ser constituída por indivíduos de faixa etária diferente dos estudos que orientaram o desenvolvimento do treinamento proposto. Os estudos utilizados como referência utilizaram participantes idosos enquanto que o presente estudo utilizou adultos jovens. Sabe-se que com o envelhecimento algumas 
funções cognitivas começam a declinar, como é o caso da atenção visual e da velocidade de processamento da informação. Neste sentido, compensar estes declínios através de um programa de estimulação cognitivo-motora que focalizasse estes aspectos parece ter sido mais promissor às amostras dos estudos de referência. Isto explicaria porque os adultos jovens não foram significativamente beneficiados pelo presente programa. O quarto fator é o tamanho reduzido da amostra $(n=22)$, que foi selecionado por conveniência, ter sido influenciado por diferenças individuais da história de aprendizagem dos motoristas. Uma amostra maior minimizaria a influência de variáveis estranhas. $\mathrm{O}$ último fator é a ausência de um segundo avaliador na avaliação prática, o que evitaria um possível resultado enviesado em função de fatores subjetivos do avaliador. Apesar de a avaliação seguir um questionário padronizado, as respostas do avaliador podem ser afetadas subjetivamente como, por exemplo, através de um eventual cansaço por parte do instrutor por estar avaliando vários sujeitos no mesmo dia. Além disto, o uso de apenas um avaliador não permite gerar um índice de concordância entre juízes que tornaria a apreciação da habilidade de dirigir mais confiável.

No que diz respeito à segunda questão da pesquisa, os resultados indicaram uma relação positiva entre a realização da estimulação cognitivo-motora e o desempenho da memória de trabalho. $\mathrm{O}$ teste OSPAN evidenciou que o grupo experimental apresentou significativa melhora nos resultados pós-intervenção quando comparado ao grupo controle, nos seguintes itens: Número Total de Palavras Lembradas, Número Total de Palavras Lembradas na Posição Correta, Número de Conjuntos de Palavras Lembrados na Posição Correta e Número de Palavras dos Conjuntos Lembrados Corretamente. Em relação ao teste de atenção (teste Trilhas formas A e B), não houve uma diferença significativa. Tanto o grupo experimental quanto o grupo controle apresentaram maior rapidez na execução da tarefa na retestagem, não podendo concluir-se que a estimulação cognitiva tenha favorecido a melhora do resultado nos participantes do grupo experimental. Este resultado pode ter sido em função do efeito de retestagem decorrentes da não disponibilidade de versões diferentes dos mesmos testes.

Por fim, deixam-se aqui registrados, a partir dos resultados obtidos com base nessa pesquisa, algumas sugestões: aplicar as intervenções propostas em um número maior de sujeitos, desenvolver a aplicação de um programa de estimulação cognitivomotora com um número maior de sessões e realizar o programa proposto com 
motoristas idosos, já que se trata da amostra que foi usada como referência nos estudos anteriores.

Considerando que estudos sobre segurança no trânsito e redução de acidentes é de grande interesse público, torna-se importante dar continuidade a esta pesquisa a fim de se verificara melhor forma de aprimorar as funções cognitivas da atenção e memória de trabalho e sua relação com uma direção segura. Buscar estratégias através de um programa de estimulação cognitivo-motora, que viabilize o incremento da habilidade de dirigir, pode ser um meio promissor de minimizar os riscos de acidentes no trânsito. 


\section{Referências}

Adrian, J., Postal, V., Moessinger, M., Rascle, N., \& Charles, A. (2011). Personality traits and executive functions related too n-road driving performance among older drivers. Accident, Analysis and Prevention, 43, 1652-1659. doi:

10.1016/j.aap.2011.03.023.

Andersen, G. J., Ni, R., Bian, Z., \& Kang, J. J. (2011).Limits of spatial attention in three-dimensional space and dual-task driving performance. Accident Analysis and Prevention, 43, 381-390. doi:10.1016/j.aap.2010.09.007.

Anderson, J. R. (2004). Psicologia Cognitiva e suas implicações experimentais. Rio de Janeiro, Brasil: LTC Editora.

Andrews, E. C., \&Westerman, S. J. (2012). Age differences in simulated driving performance: Compensatory processes. Accident Analysis and Prevention, 45, 660668. doi: 10.1016/j.aap.2011.09.047.

Anstey, K. J., \& Wood, J. (2011). Chronological age and age-related cognitive deficits are associated with an increase in multiple types of driving errors in late life. Neuropsychology, 25 (5), 613-621. doi: 10.1037/a0023835.

Anstey, K. J., Horswill, M. S., Wood, J., \& Hatherly, C. (2012).The role of cognitive and visual abilities as predictors in the multifactorial model of driving safety. Accident Analysis and Prevention,45, 766-774. doi:10.1016/j.aap.2011.10.006.

Asimacopulos, J., Boychuck, Z., Sondegaard, D., Poulin, V., Ménard, I., \& KornerBitensky, N. (2012). Assessing executive function in relation to fitness to drive: A review of tools and their ability to predict safe driving. Australian Occupational Therapy Journal, 59, 402-427. doi:10.1111/j.1440-1630.2011.00963.x.

Barulli, D., \& Stern, Y. (2013). Efficiency, capacity, compensation, maintenance, plasticity: Emerging concepts in cognitive reserve. Trends in Cognitive Sciences, xx, 1-8. doi: 10.1016/j.tics.2013.08.01.

Bealand, V., Goode, N., Salmon, P. N., \&Lenné, M. G. (2013). Is there a case for driver training? A review of the efficacy of pre- and post-license driver training. Safety Science, 51, 127-137. doi10.1016/j.ssci.2012.06.021.

Boccara, V., Delhomme, P., Vigal-Gomel, C., \& Rogaslki, J. (2011). Development of student drivers's self-assessment accuracy during French driver training: Selfassessments compared to instructors`assessments in three risky driving situations. Accident Analysis \& Prevention, 43, 1488-1496. doi:10.1016/j.aap.2011.02.029. 
Brookhuis, K. A., \& Waard, D. (2010).Monitoring drivers' mental workload in driving simulators using physiological measures. Accident Analysis \& Prevention, 42, 898903. doi: 10.1016/j.aap.2009.06.001.

Bunce, D., Young, M., Blane, A., \& Khugputh, P. (2012). Age and inconsistency in driving performance. Accident Analysis \& Prevention, 49, 293-299. doi: 10.1016/j.aap.2012.01.001.

Cassavaugh, N. D., \& Kramer, A. F. (2009). Transfer of computer-based to simulated driving in older adults. Applied Ergonomics, 40, 943-952. doi:10.1016/j.apergo.2009.02.001.

Casutt, G., Martin, M., Keller, M., \& Jancke, L. (2014).The relation between performance in on-road driving, cognitive screening and driving simulator in older healthy drivers. Transportation Research Part F, 22, 232-244. doi:10.1016/j.trf.2013.12.007.

Chariglione, I.P.F. \& Janczura, G.A. (2013). Contribuições de um treino cognitivo para a memória de idosos institucionalizados. Psico-USF, 18 (1), 13-22.

Charlton, S. G., \& Starkey, N. J. (2011). Driving without awareness: The effects of practice and automaticity on attention and driving. Transportation Research Part F, 14, 456-471. doi:10.1016/j.trf.2011.04.010.

Chodzko-Zajko, W. J., \& Moore, K. A. (1994). Physical fitness and cognitive functioning in aging. Exercise and Sport Sciences Reviews, 22, 195-220.

Colcombe, S. J., Erickson, K. I., Scalf, P. E., Kim, J. S., Prakash, R., McAuley, E., \& Kramer, A. F. (2006). Aerobic exercise training increases brain volume in aging humans. The Journals of Gerontology. Series A, Biological Sciences and Medical Sciences, 61(11), 1166-1170. doi: 10.1093/gerona/61.11.1166.

Dahlin E., Nyberg L., Backman, L., \& Neely, A. S. (2008). Plasticity of executive functioning in young and older adults: Immediate training gains, transfer, and longterm maintenance. Psychology and Aging, 23 (4), 720-730. doi: 10.1037/a0014296.

Devlin, A., McGillivraya, J., Charlton, J., Lowndes, G., \& Etienne, V. (2012). Investigating driving behaviour of older drivers with mild cognitive impairment using a portable driving simulator. Accident Analysis and Prevention, 49, 300-307. doi: 10.1016/j.aap.2012.02.022.

Edwards, J. D., Myers, C., Ross, L. A., Roenker, D. L., Cissel, G. M., McLaughlin. A. M., \& Ball, K. K. (2009). The longitudinal impact of cognitive speed of processing 
training on driving mobility. The Gerontologist, 49 (4), 485-494 doi:10.1093/geront/gnp042.

Fabre, C., Chamari, K., Mucci, P., Masse-Biron, J., \&Prefaut, C. (2002). Improvement of cognitive function by mental and/or individualized aerobic training in healthy elderly subjects. International Journal of Sport Medicine, 23 (6), 415-421. doi: $10.1055 / \mathrm{s}-2002-33735$.

Fafanova, J., \&Vollrath, M. (2011). Distraction while driving: The case of older drivers. Transportation Research Part F, 14, 638-648. doi:10.1016/j.trf.2011.08.005.

Fort, A., Martin, R., Jacquet-Andrieu, A., Combe-Pangaud, C., Foliot, G, Daligault, S., \&Delpuech, C. (2010). Attention demand and processing of relevant visual information during simulated driving: A MEG study. Brain Research, 1363, 117127. doi:10.1016/j.brainres.2010.09.094.

Garrison, T. M., \& Willians, C. C. (2013).Impact of relevance and distraction on driving performance and visual attention in a simulated driving environment. Applied Cognitive Psychology, 27, 396-405.doi: 10.1002/acp.2917.

Gaspar, J. G., Neider, M. B., Simons, D. J., McCarley, J. S., \& Kramer, A. F. (2013). Change detection: Training and transfer. Plos One, 8 (6) e67781.doi:10.1371/journal.pone.0067781.

Hancock, P. A., Kane, M. J., Scallen, S., \& Albinson, C. B. (2002). Effects of gender and athletic participation on driving capability. International Journal of Occupational Safety and Ergonomics, 8 (2), 281-292. doi: 10.1080/10803548.2002.11076529

Hawkins, H. L., Kamer, A. F., \& Capaldi, D. (1992). Aging, exercise and attention. Psychology Aging, 7 (4), 643-653.doi:10.1037/0882-7974.7.4.643.

Huang, J. I., \& Ford, J. K. (2012). Driving locus of control and driving behaviors: inducing change through driver training. Transportation Research Part F, 15, 358368. doi: 10.1016/j.trf.2011.09.002.

Henderson, S., Gagnon, S., Bélanger, A., Tabone, R., Collin, C., \& Ford, J. K. (2010). Near peripheral motion detection threshold correlates with self-reported failures of attention in younger and older drivers. Accident Analysis and Prevention, 42, 11891194. doi: 10.1016/j.aap.2010.01.009. 
Ishimatsu, K., Miura, T., \& Shinohara, K. (2010). Age influences visual attention characteristics among accident-free and accident-involved drivers. Japanese Psychological Research, 52 (3), 186-200. doi: 10.1111/j.1468-5884.2010.00437.x.

Isler, R. B., Sterkey, N. J., \& Sheppard, P. (2011). Effects of higher-order driving skill training on young, inexperienced driver's on-road driving performance. Accident Analysis and Prevention, 50, 438-444. doi: 10.1016/j.aap.2011.04.017.

Jacson, M. L., Croft, R. J., Kennedy, G. A., Owens, K., \& Howard, M. E. (2013). Cognitive components of simulated driving performance: Sleep loss effects and predictors. Accident Analysis and Prevention, 43, 1818-1827. doi: 10.1016/j.aap.2012.05.020.

Jaeggi S. M., Buschkuehl M., Jonides, J., \& Shah, P. (2011). Short- and long-term benefits of cognitive training. PNAS, 108 (25), 10081-10086. doi: 10.1073/pnas.1103228108.

Klonoff, P. S., Olson, K. C., Talley, M. C., Husk, K. L., Myles, S. M., Gehrels, J. A., \& Dawson, L. K. (2010). The relationship of cognitive retraining to neurological patients' driving status: The role of process variables and compensation training. Brain Injury, 24 (2), 63-73. doi: 10.3109/02699050903512863.

Lenné, M. G., Liu, C. C., Salmon, P. M., Holden, M., \& Moss, S. (2011). Minimizing risks and distractions for young drivers and their passengers: A evaluation of a novel driver-passenger training program. Transportation Research Part F, 14, 447455. doi:10.1016/j.trf.2011.08.001.

Leversen, J. S. R., Hopkins, B., \& Sigmundsson, H. (2013). Ageing and driving: examining the effects of visual processing demands. Transportation Research Part F, 17, 1-4. doi: 10.1016/j.trf.2012.11.003.

Magill, R. (2003). Motor learning and control, concepts and applications (7th ed.). New York, EUA: McGraw-Hill.

Marmeleira, J. F., Godinho, M. B., \& Fernandes, O. M. (2009). The effects of exercise program on several abilities associated with driving performance in older adults. Accident Analysis and Prevention, 41, 90-97. doi: 10.1016/j.aap.2008.09.008.

Marmeleira, J. F., Fernandes, O. M., Tlemcani, M., \& Godinho, M. B. (2011). Exercise can improve speed of behavior in older drivers. Journal of Aging and Physical Activity, 19, 48-61. doi: 10.1123/japa.19.1.48. 
Matos, R., \& Godinho, M. (2009). Useful field of vision and peripheral reaction time in novice drivers: Transfer to a real driving situation after a perceptual-motor training program. Advances in Transportation Studies an International Journal Section B, 19, 77-84.

Meeusen, R. (2005). Exercise and the brain: Insight in new therapeutic modalities. Annals of Transplantation: Quarterly of the Polish Transplantation Society , 10(4), $49-51$.

Oswald, W. D., Rupprecht, R., Gunzelmann, T., \& Tritt, K. (1996). The SIMA-project: Effects of 1 year cognitive and psychomotor training on cognitive abilities of the elderly. Behavioural Brain Research, 78(1), 67-72. doi: 10.1016/01664328(95)00219-7.

Ott, B. R., Davis, J. D., Panpandonatos, G. D., Hewitt, S., Festa, E. K., Heindel, W. C., $\&$ Carr, D. B.(2013). Assessment of driving-related skills prediction of unsafe driving in older adults in the office setting. The American Geriatrics Society, 61, 1164-1169. doi: 10.1111/jgs. 12306.

Perumparaichallai, R. K., Husk, K. L., Myles, S. M., \& Klonoff, P. S. (2014).The relationship of neuropsychological variables to driving status following holistic neurorehabilitation. Frontiers in Neurology, 5 (56), 1-

7.doi:10.3389/fneur.2014.00056.

Pierce, R. S., \& Andersen, G. J. (2014). The effects of age and workload on 3D spatial attention in dual-task driving. Accident Analysis and Prevention, 67, 96-104. doi: 10.1016/j.aap.2014.01.026.

Recarte, M. A., \&Nunes, L. M. (2003). Mental workload while driving: Effects on visual search, discrimination, and decision making. Journal of Experimental Psychology, 9 (2), 119-137. doi: 10.1037/1076-898X.9.2.119.

Redick, T. S., Shipstead, Z., Harison,T. L., Hicks, K. L., Hambrick, D. Z., Kane, M. J., \& Engle, R. W. (2013). No evidence of intelligence improvement after working memory training: A randomized, placebo-controlled study. Journal of Experimental Psychology General, 142(2),359-379. doi: 10.1037/a0029082.

Reimer, B., Mehler, B., Wang, Y., \& Coughlin, J. F. (2012). A field study on the impact of variations in short term memory demands on drivers' visual attention and driving across processes three age groups. Human Factors, 54 (3), 454-468. doi: 10.1177/0018720812437274. 
Reitan, R. M. (1958). Trail Making Test: Manual for Administration Scoring and Interpretation. Indianapolis, IN: Indiana. University Medical Center.

Romer, D., Lee, Y., McDonald, C. C., \& Winston, F. K. (2013). Adolescence, Attention allocation and driving safety. Journal of Adolescent Health, 54, S6 e S15.doi:10.1016/j.jadohealth.2013.10.202.

Ross, V., Jongen, E. M. M., Wang, W., Brijs, T., \& Brijs, K. (2013). Investigating the influence of working memory capacity when driving behavior is combined with cognitive load: Na LCT study of young novice drivers. Accident, Analysis and Prevention.doi: 10.1016/j.aap.2013.06.032.

Ross, L. A., Edwards, J. D., O’Connor, M. L., Ball, K. K. , Wadley, V. G., \&Vance, D. E. (2015). The transfer of cognitive speed of processing training to older adults' driving mobility across 5 years. Journals of Gerontology, Series B: Psychological Sciences and Social Sciences, 71 (1)87-97 doi:10.1093/geronb/gbv022.

Roth, D, L., Goode, K, T., Clay, O. J., \& Ball, K. (2003).Association of physical activity and visual attention in older adults. Aging Health, 15 (3), 534-547. doi: $10.1177 / 0898264303253512$.

Sakai, H., Takahara, M., Honjo, N. F., Doi, S., Sadato, N., \& Uchiyama, Y. (2012). Regional frontal gray matter associated with executive function capacity as a risk for vehicle: Crashes in normal adult. Plos One, 7 (9), 1-6. doi: 10.1371/journal.pone.0045920.

Shanmugaratnam, S., Kass, S. J., \& Arruda, J. E. (2010). Age differences in cognitive and psychomotor abilities and simulated driving. Accident, Analysis and Prevention, 42 (3), 802-808. doi:10.1016/j.aap.2009.10.002.

Silva, M. T., Laks, J., \& Engelhardt, E. (2009). Neuropsychological tests and driving in dementia: a review of the recent literature. Revista da Associação Médica Brasileira. 55 (4). 484-488 doi: 10.1590/S0104-42302009000400027

Smith, E.E,. \& Kosslyn, S.M. (2008). Cognitive Psychólogy: Mind and Brain. New Delhi, India: Prentice-Hall of India.

Smith, G. E., Housen, P., Yaffe, K., Ruff, R., Kennison, R. F., Mahncke, H. W., \& Zelinski, E. M. (2009). A cognitive training program based on principles of brain plasticity: Results from the improvement in memory with plasticity-based adaptive cognitive training (IMPACT) study. Journal of the American Geriatrics Society, 57, 594-603. doi: 10.1111/j.1532-5415.2008.02167.x. 
Son, J., Reimer, B., Mehler, B., Pohlmeyer, A. E., Godfrey, K. M., Orszulak, J., \& Coughlin, J. F. (2009). Age and cross-cultural comparison of drivers' cognitive workload and performance in simulated urban driving. International Journal of Automotive Technology,11(4), 533-539. doi: 10.1007/s12239-010-0065-6.

Soliman, A. M., \& Mathna, E. K. (2009). Metacognitive strategy training improves driving situation awareness. Social Behavior and Personality, 37(9), 1161-1170. doi: 10.2224/sbp.2009.37.9.1161.

Shanmugaratnam, S., Kass, S. J., \& Arruda, J. E. (2010). Age differences in cognitive and psychomotor abilities and simulated driving. Accident, Analysis and Prevention, 42, 802-808. doi:10.1016/j.aap.2009.10.002.

Sternberg, R. J. (2010). Psicologia cognitiva. Porto Alegre: Brasil. Artes Médicas.

Stinchcombe, A., \& Gagnon, S. (2013). Aging and driving in a complex world: Exploring agesdifferences in attentional demand while driving. Transportation Research Part F, 17, 125-133. doi: 10.1016/j.trf.2012.11.002.

Swain, R. A., Harris, A. B., Wiener, E.C., Dutka, M.V., Morris, H.D., Theien, B.E., \& Greenough, W. T., (2003). Prolonged exercise induces angiogenesis and increases cerebral blood volume in primary motor cortex of the rat. Neuroscience, 117(4), 1037-1046. doi: 10.1016/S0306-4522(02)00664-4.

Unsworth, N., Heitz, R.P, Schrock, J.C., \& Engle, R. W. (2005). An automated version of the operation span task, Behavior Research Methods, 37 (3), 498-505.

Verster, J. C., Bervoets, A. C., Klerk, S., \& Roth, T. (2014). Lapses of attention as outcome measure of the on-the-road driving test. Psychopharmacology, 231, 283292. doi: 10.1007/s00213-013-3236-0.

Wild-Wall, N., Hahn, M., \& Falkenstein, M. (2011). Preparatory processes and compensatory effort in older and younger participants in a driving-like dual task.Human Factors, 53 (2), 91-102. doi: 10.1177/0018720811402068.

Werneke, J., \&Vollrath, M. (2012). What does the driver look at? The influence of intersection characteristics on attention allocation and driving behavior.Accident, Analysis and Prevention, 45, 610-619. doi:10.1016/j.aap.2011.09.048.

Wood, J.M., \& Owsley, C. (2014).The useful field of view test. Geronlogoly, 60, 315-318. doi: 10.1159/000356753. 
Yamani, Y., Samuel, S., Knodler, M. A., \& Fisher, D. L. (2016). Evaluation of the effectiveness of a multi-skill program for training younger driver on higher cognitive skills. AppliedErgonomic, 52, 135-141.

doi:10.1016/j.apergo.2015.07.005. 
Apêndice A

\section{Termo de Consentimento Livre e Esclarecido}

Você está sendo convidado a participar da pesquisa “O EFEITO DE UM PROGRAMA DE ESTIMULAÇÃO COGNITIVO-MOTORA NA HABILIDADE DE DIRIGIR EM ADULTOS JOVENS", de responsabilidade de Michelle Cristina Mattoso Brandt de Araújo Lima, aluna de mestrado da Universidade de Brasília. O objetivo desta pesquisa é avaliar a eficácia de um programa de estimulação cognitivo-motora em melhorar a atenção, a memória de trabalho e a habilidade de dirigir. Assim, gostaria de consultálo(a) sobre seu interesse e disponibilidade de cooperar com a pesquisa.

Você receberá todos os esclarecimentos necessários antes, durante e após a finalização da pesquisa, e lhe asseguro que o seu nome não será divulgado, sendo mantido o mais rigoroso sigilo mediante a omissão total de informações que permitam identificá-lo(a). Os dados provenientes de sua participação na pesquisa, tais como questionários, entrevistas, testes neuropsicológicos, ficarão sob a guarda do pesquisador responsável pela pesquisa.

A coleta de dados será realizada por meio de realização de avaliação da prática de dirigir por meio de carro e instrutor de autoescola percorrendo um circuito próximo à universidade e com duração de 15 minutos. Realização de um teste de atenção de aproximadamente 15 minutos, dois testes de memória de trabalho com duração total de aproximadamente 20 minutos. Participação em um programa de estimulação cognitivomotora contendo 5 encontros com duração de aproximadamente 1:30 hora cada encontro. Uma nova testagem será realizada em aproximadamente 20 dias após a primeira testagem. É para estes procedimentos que você está sendo convidado a participar. Sua participação na pesquisa não implica em nenhum risco.

Sua participação é voluntária e livre de qualquer remuneração ou benefício. Você é livre para recusar-se a participar, retirar seu consentimento ou interromper sua participação a qualquer momento. A recusa em participar não irá acarretar qualquer penalidade ou perda de benefícios.

Se você tiver qualquer dúvida em relação à pesquisa, você pode me contatar através do telefone 61 99234-6666 ou pelo e-mail michelle.neurociencias@gmail.com. 
A equipe de pesquisa garante que os resultados do estudo serão devolvidos aos participantes por meio de e-mail, podendo ser publicados posteriormente na comunidade científica.

Este projeto foi revisado e aprovado pelo Comitê de Ética em Pesquisa do Instituto de Ciências Humanas da Universidade de Brasília - CEP/IH sob o número CAAE: 60893816.8.0000.5540. As informações com relação à assinatura do TCLE ou os direitos do sujeito da pesquisa podem ser obtidos através do e-mail do CEP/IH cep_ih@unb.br.

Este documento foi elaborado em duas vias, uma ficará com o(a) pesquisador(a) responsável pela pesquisa e a outra com o senhor(a).

Assinatura do (a) participante

Assinatura do (a) pesquisador (a)

Brasília, de de 


\section{Apêndice B}

Nome:

Data da aplicação: I

Avaliação da Habilidade de Dirigir

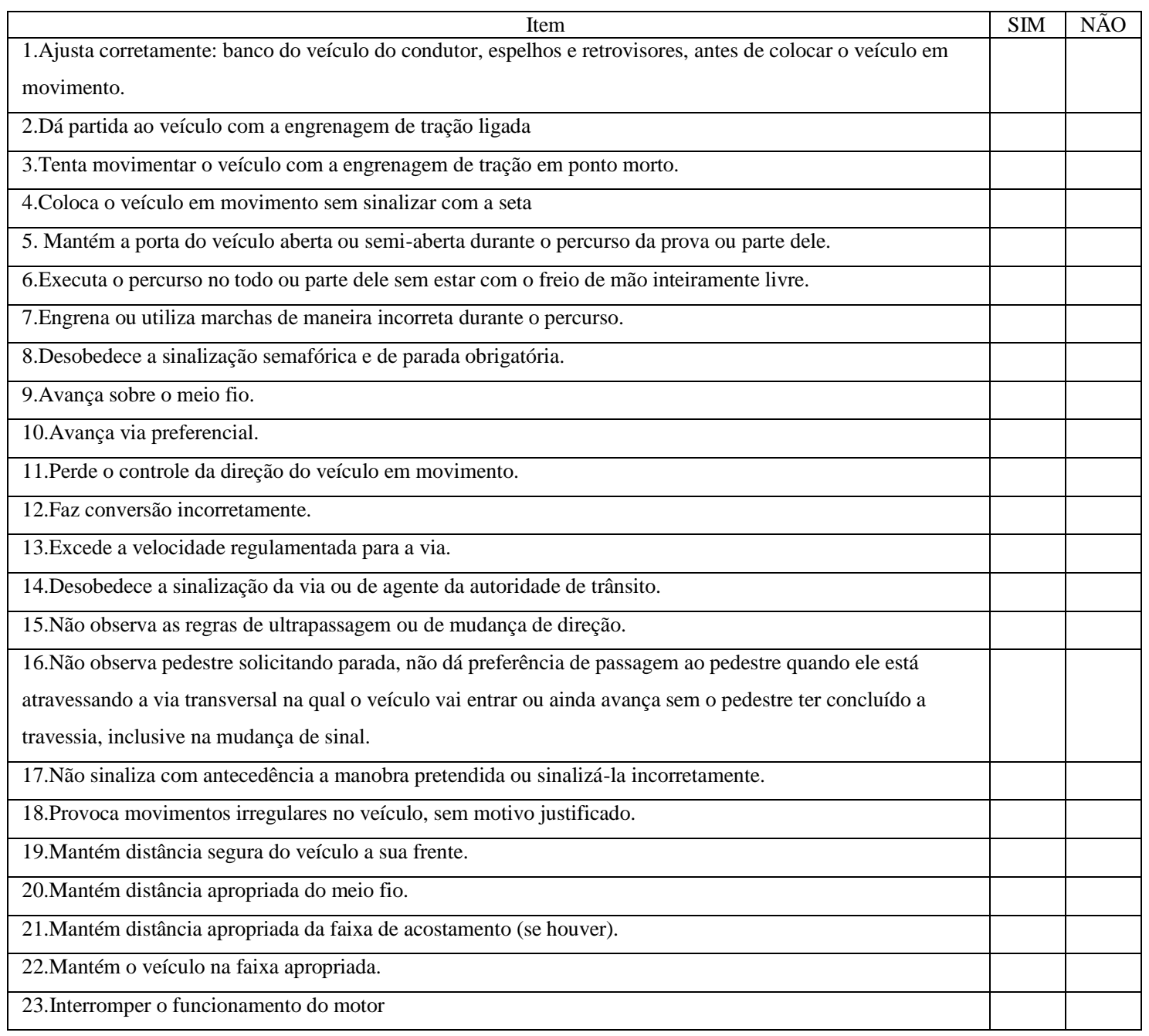


Apêndice C

\section{Procedimentos do Programa de Estimulação Cognitivo-Motora}

Sessão 1: o objetivo desta sessão foi apresentar a proposta de um programa de estimulação cognitivo-motora. A atividade de psicoeducação tratou dos temas a serem abordados nas demais sessões: atenção, memória de trabalho e controle motor. O exercício prático visou aprimorar o controle atencional (visual e auditivo) e o controle motor.

Exercícios Práticos: inicialmente, cada participante pegou um balão e o manteve no ar (rebatendo) enquanto um som ambiente de uma rua com tráfego foi apresentado. Ao longo da sessão mais balões foram inseridos. Os participantes trabalharam em equipe para que todos os balões estivessem no ar durante a apresentação da pista.

$\mathrm{Na}$ fase de familiarização, os participantes rebateram um balão azul enquanto ouviam o som ambiente de tráfego (30 segundos). Eles realizaram esta atividade por duas vezes. Posteriormente, ainda na fase de familiarização, a atividade foi reiniciada com cada participante rebatendo simultaneamente dois balões. Neste momento, a apresentação do som durou 45 segundos. Esta tarefa também foi realizada por duas vezes. $\mathrm{O}$ tempo total desta fase foi de aproximadamente 5 minutos.

Durante a fase de treino, os participantes rebateram 1, 2 ou 3 balões em um intervalo de tempo de 30 segundos, 45 segundos e 1 minuto, respectivamente. Foram realizadas 3 rodadas com 1 balão, 6 rodadas com 2 balões e mais 6 rodadas com 3 balões. O tempo total da fase de treino foi de, aproximadamente, 20 minutos.

Tarefas do experimentador:Organizar a sala posicionando 5 cadeiras em forma de $U$ todas de frente para o quadro branco localizado à frente e ao centro da sala de aula. (nas demais sessões do treinamento este procedimento foi repetido). Encher 20 balões na cor azul. Colocar cinco balões no chão, ao centro das cadeiras. Os demais balões foram colocados em um canto da sala para que não interferissem no espaço da atividade. A inclusão de novos balões para a realização da atividade foi realizada pelos próprios participantes que, após o comando do experimentador, iam até o local onde estavam os balões e os pegavam para a realização da atividade. O tempo aproximado para adquirir novos balões e reiniciar o exercício foi 1 minuto. A pista sonora era apresentada por meio de gravação de áudio via computador nos tempos de 30 segundos, 45 segundos e 1 minuto. 
O experimentador explicou o desenvolvimento do exercício, realizando rodadas de familiarização com a tarefa e avaliou se todos os participantes compreenderam a atividade. Primeiramente, distribuiu um balão para cada participante e, após, apresentou a pista sonora em um intervalo de tempo de 30 segundos. Realizou esta atividade por duas vezes. Em um segundo momento, distribuiu mais dois balões por participante e, após, apresentou a pista sonora com duração de 45 segundos. Esta tarefa foi realizada por mais duas vezes. O tempo de pausa e reinício da atividade com o mesmo número de balões foi de 30 segundos e o tempo de inclusão de novos balões para a realização da atividade foi de, aproximadamente, 2 minutos. Feito isto, o experimentador deu início à fase de treinamento com duração de, aproximadamente, 5 minutos.

$\mathrm{Na}$ fase de treino, o experimentador inseriu as pistas e os balões conforme aprendizado anterior e, ao final do exercício, aplicou mais seis rodadas com uma pista sonora com duração de 1 minuto e três balões por participante. O tempo total desta tarefa foi de, aproximadamente, 20 minutos.

As instruções da tarefa na fase de familiarização foram as seguintes: "Vocês deverão pegar um balão azul e segurá-lo. Eu vou apresentar para vocês um som de trânsito, semelhante ao que vocês escutam quando estão dirigindo. Enquanto vocês estiverem ouvindo esse som deverão rebater o balão no ar, sem deixá-lo cair. Se o balão cair no chão, você deverá pegá-lo e retomar a atividade. Quando o som cessar, vocês pararão de rebater e segurarão o balão com as mãos. Em seguida eu vou entregar mais 1 balão para cada um de vocês e vocês terão que rebatê-los de maneira que não caiam no chão. Caso algum balão caia no chão durante o exercício, vocês deverão pegá-lo e continuar a rebatê-los. Vocês deverão trabalhar em equipe não deixando que nenhum balão caia no chão. Compreenderam? Alguma Dúvida? Podemos começar?"

As instruções da tarefa na fase de treino foram as seguintes: "Agora que vocês compreenderam a atividades nós vamos iniciar o treino. Vamos começar a atividade apenas com um balão. Por favor, coloquem um dos dois balões junto àqueles outros que estão no canto da sala. Eu vou colocar o mesmo som de trânsito que vocês ouviram e vocês terão que rebater o balão no ar, sem deixá-lo cair. Se o balão cair no chão, você deverá pegá-lo e retomar a atividade. Vamos começar com um balão e depois vamos fazer a atividade com dois balões por pessoa e finalmente faremos com três balões por pessoa. Caso algum balão caia no chão durante o exercício, vocês deverão 
pegá-los e voltar a rebatê-los. Vocês deverão trabalhar em equipe não deixando que nenhum balão caia no chão. Compreenderam? Alguma Dúvida? Podemos continuar? ”

Sessão 2: a sessão teve como objetivo apresentar o conceito de controle motor e aprimorar o controle motor grosso. A atividade de psicoeducação abordou o controle motor grosso e sua importância na habilidade de dirigir. O exercício prático teve como foco desenvolver um melhor controle motor grosso.

Exercícios Práticos: os participantes responderam de forma gestual a várias perguntas sobre dirigir, ou seja, usaram os braços ou as pernas para representar movimentos corporais apropriados e associados ao ato de dirigir. As perguntas foram apresentadas verbalmente pelo experimentador, conforme descrito abaixo. Durante o exercício, os participantes permaneceram sentados em cadeiras individuais. A atividade iniciou-se com os participantes sentados nas cadeiras simulando (imaginando) estarem segurando um volante de carro com as duas mãos. Na fase de familiarização foi solicitado aos participantes realizar os movimentos de pernas e braços necessários para dirigir um automóvel: frear, fazer o câmbio, acelerar, assim como gestos de virar à esquerda ou direita. Cada pergunta-resposta na fase de familiarização foi repetida 5 vezes de forma alternada. Após verificar que os participantes haviam executado corretamente os movimentos corporais apropriados, foi iniciada a fase de treino. Na fase de treino foram apresentadas verbalmente algumas situações associadas ao dirigir. A tarefa dos participantes foi realizar os movimentos apropriados aprendidos na fase de familiarização. Ao final do exercício o experimentador simulou um guarda de trânsito em atuação e a tarefa dos participantes foi realizar os movimentos corporais adequados em resposta aos comandos do guarda.

Tarefas do Experimentador: apresentar verbalmente as atividades a serem realizadas pelos participantes, conforme descritas na fase de familiarização. Certificarsede que os participantes conheciam os movimentos principais das pernas e braços necessários para dirigir um automóvel, solicitando a sua execução e, em seguida,fazendo uma demonstração. Na fase de treino, cada situação associada ao dirigir foi apresentada 5 vezes alternadamente. Os gestos praticados pelo experimentador simulando um guarda de trânsito foram realizados por 5 vezes alternadamente.

As instruções da tarefa na fase de familiarização foram as seguintes: "Nós vamos trabalhar os movimentos corporais necessários quando estamos dirigindo e para isso vamos usar nossa imaginação e criatividade. Vocês vão sentar em uma dessas cadeiras 
e vão imaginar que estão sentados no banco do motorista de um carro. Eu vou fazer algumas perguntas sobre os movimentos com braços e pernas que precisamos fazer quando estamos dirigindo. A tarefa de vocês, portanto, será de responder às minhas perguntas realizando os movimentos adequados de braços ou pernas como se estivessem dirigindo. Certo? Alguma dúvida?"

As perguntas realizadas na fase de familiarização com a tarefa foram as seguintes:

- Em que posição fica o pedal do acelerador (esquerda, meio ou direita)? Faça o movimento de acelerar com o pé apropriado. (Resposta: direita)

- Em que posição fica o pedal do freio (esquerda, meio ou direita)? Faça o movimento de frear com o pé apropriado. (Resposta: meio)

- Em que posição fica o pedal da embreagem (esquerda, meio ou direita)? Faça o movimento de frear com o pé apropriado. (Resposta: esquerda)

- Você está com o pisca-pisca pifado. Como é o movimento do braço como aviso de que seu carro vai virar à direita?

- Você está com o pisca-pisca pifado. Como é o movimento do braço como aviso de que seu carro vai virar à esquerda?

- Como é o movimento do braço solicitando para o motorista de trás diminuir a velocidade?

- Vire à direita! Como é o movimento do volante para que possa virar o carro para a direita?

- Vire à esquerda! Como é o movimento do volante para que possa virar o carro para a esquerda?

- Como é o movimento de passar a marcha? Use o pé e a mão sequencialmente. (Resposta: primeiro a embreagem, após engrenar a marcha e, a seguir, soltar a embreagem e acelerar)

As instruções da tarefa na fase de treino foram as seguintes: "Agora que vocês compreenderam a atividade, eu vou refazer as perguntas e vocês irão responder gestualmente de forma adequada! Tudo bem? Podemos Começar?"

As situações apresentadas pelo experimentador associadas ao dirigir foram as seguintes: (a) o pisca-pisca do seu carro está quebrado. Sinalize gestualmente que você vai virar à direita; (b) o pisca-pisca do seu carro está quebrado. Sinalize gestualmente que você vai virar à esquerda; (c) você quer solicitar gestualmente ao motorista do 
veículo de trás de seu carro que diminua a velocidade. Como você faria isto? (d) você está acelerando o carro. Faça o movimento de acelerar com o pé apropriado; (e) você está freando o carro. Faça o movimento de frear com o pé apropriado; (f) você está ultrapassando um carro e para isso precisa mudar de marcha. Faça o movimento apropriado com os pés e braços; (g) você está subindo uma ladeira e o trânsito parou. Faça os movimentos necessários para você se manter parado na ladeira; (h) o sinal está mudando do verde para o vermelho. Você precisa frear e colocar o câmbio no ponto morto. Faça os movimentos adequados.

$\mathrm{Na}$ segunda etapa do exercício o experimentador forneceu as seguintes instruções: “Agora eu sou um guarda de trânsito e vou fazer alguns gestos com meus braços e sinais de apito referentes a parar, seguir, diminuir a marcha. Vocês sabem me dizer o que significam esses gestos? (Demonstrar como são feitos cada movimento). Quando eu fizer o gesto vocês terão que representar o movimento apropriado com pés elou braços.". A seguir, o experimentador executou os gestos de pare, siga e diminua a marcha.

Sessão 3: a sessão teve como objetivo retomar o conceito de atenção e aprimorar o controle atencional (visual e auditivo) e motor. A atividade de psicoeducação abordou o conceito de controle atencional e controle motor e suas relações com o aprendizado da habilidade de dirigir.

Exercícios Práticos: ao chegar à sala de treinamento, cada participante pegou um balão na cor branca e um na cor roxa para início da atividade. A tarefa do participante foi manter os balões no ar (rebatendo) enquanto um som ambiente de uma rua com tráfego foi apresentado. Ao detectar uma pista específica (som de sirene de ambulância ou buzina de carro ou buzina de caminhão ou freada), o participante realizou uma das seguintes ações: segurar o balão branco (pista: som de buzina de caminhão), segurar o balão roxo (pista: som de buzina de carro), deixar os dois balões caírem no chão (pista: som de sirene de ambulância) ou segurar os dois balões (som de freada).

A fase de familiarização foi realizada em cinco etapas. Na primeira etapa foi apresentado um som ambiente de tráfego por um período de 45 segundos sendo solicitado aos participantes para rebaterem os dois balões simultaneamente até que a pista sonora cessasse. Esta etapa foi semelhante ao exercício realizado na sessão 1. A atividade foi realizada por três vezes. Após a apresentação de cada pista, houve uma 
pausa sem apresentação de áudio por 10 segundos. O tempo total desta etapa foi de, aproximadamente, 3 minutos. Na etapa seguinte, foram introduzidas as pistas sonoras para mudanças de ação. Nesta fase, enquanto os participantes ouviam o som do tráfego, foi introduzido outro som (pistas sonoras especificadas descritas acima) sendo cada um associado às ações específicas. Primeiro os participantes ouviram um som de buzina de carro. No momento que os participantes ouvissem esta pista, deveriam parar de rebater os balões, segurar o balão roxo e deixar cair o balão branco. Esta tarefa foi realizada apresentando a pista "buzina de carro" por 3 segundos e por três vezes, com pausa de 5 segundos entre cada apresentação da pista. O tempo total desta atividade foi de, aproximadamente, 30 segundos. Foram feitos treinos alternando o som de tráfego com a pista "buzina de carro" perfazendo quatro repetições de treino, com pausas de 10 segundos entre cada rodada, em um tempo aproximado de 4 minutos. Os tempos de apresentação, pausa e total foram idênticos para as demais pistas descritas a seguir.

Após as rodadas descritas acima, os participantes ouviram um som de sirene de ambulância. Ao ouvir este som, os participantes deveriam deixar os dois balões caírem. Esta tarefa foi realizada apresentando a pista "sirene de ambulância" (4) Em seguida, foi apresentada a pista "freada de carro". Ao ouvirem este som, os participantes deveriam segurar os dois balões. (5) Após esta tarefa, houve a apresentação da pista "buzina de caminhão”. Ao ouvir este som, os participantes deveriam segurar o balão branco e deixar cair o roxo.

O tempo total da parte prática foi de, aproximadamente, 25 minutos.

$\mathrm{Na}$ fase de treino as pistas foram apresentadas aleatoriamente. Primeiramente foram realizadas seis rodadas, com apresentação de duas pistas em cada rodada, em um tempo total de 10 minutos. Posteriormente foram realizadas 8 rodadas, com apresentação de três pistas em cada rodada, em um tempo total de 10 minutos.

Tarefas do experimentador: encher 10 balões na cor branca e 10 na cor roxa. Colocar os balões no chão, no final da sala, para não atrapalhar a locomoção dos participantes. O experimentador solicitou que cada participante pegasse um balão roxo e um branco e se dirigisse ao centro da sala.

As instruções da tarefa na fase de familiarização para a pista "som de ambiente com tráfego" foram: "Cada um de vocês deverá pegar um balão branco e outro roxo. Eu vou apresentar para vocês um som de trânsito, semelhante ao que vocês escutaram na sessão anterior. Enquanto vocês estiverem ouvindo esse som, deverão rebater os 
balões no ar sem deixá-los cair. Quando o som parar, vocês deverão parar de rebater e segurar o balão com as mãos. Certo? Alguma Dúvida? Podemos começar? ”

As instruções da tarefa na fase de familiarização para a pista "mudanças de ação" foram: "Eu vou colocar outro som e vocês vão me dizer que som que é este (apresentava-se um som de buzina de carro e se esperava a resposta dos participantes). Quando vocês ouvirem esse som de buzina de carro, vocês vão parar de rebater os balões. Vão segurar o balão roxo (e deixar cair o balão branco). Certo?”

"Agora, eu vou colocar o som do tráfego e no meio da apresentação irá aparecer o som de buzina de carro. Enquanto vocês tiverem ouvindo o som do trânsito, deverão rebater os dois balões. Quando surgir o som buzina de carro, vocês vão segurar o balão roxo e deixar cair o balão branco, certo?

"Agora eu vou colocar outro som. Que som é este? (apresentava-se um som de sirene de ambulância). Quando vocês ouvirem esse som de sirene de ambulância, vocês deverão deixar os dois balóes caírem no chão."

"Agora, eu vou colocar o som do tráfego e no meio da apresentação irá aparecer o som de sirene de ambulância. Enquanto vocês tiverem ouvindo o som do trânsito, deverão rebater os dois balôes. Quando surgir o som da sirene, vocês vão deixar os dois balões caírem no chão, certo?"

"Vamos continuar! Eu vou apresentar mais um som. Que som é este? (apresentava-se um som de freada e se esperava que os participantes respondessem). Quando vocês ouvirem esse som de freada deverão segurar os dois balões. Compreenderam?

“Agora, eu vou colocar o som do tráfego e no meio da apresentação irá aparecer o som de freada. Enquanto vocês tiverem ouvindo o som do trânsito, deverão rebater os dois balões. Quando surgir o som da freada, vocês vão segurar os dois balões, certo?"

E este som? (apresentava-se o som de freada e se esperava pela resposta dos participantes). Que som é? Quando vocês ouvirem o som buzina de caminhão, vocês deverão segurar o balão branco (e deixar cair o roxo). ',

“Agora, eu vou colocar o som do tráfego e no meio da apresentação irá aparecer o som de buzina de carro. Enquanto vocês tiverem ouvindo o som do trânsito, deverão rebater os dois balões. Quando surgir o som buzina de caminhão, vocês vão segurar o balão branco (e deixar cair o balão roxo), certo? 
As instruções da tarefa na fase de treino serão as seguintes: "Agora que vocês já treinaram todos os sons separadamente, eu vou apresentar esses mesmos sons de forma aleatória. A tarefa de vocês será, ao ouvirem um som específico,realizar as ações apropriadas que foram treinadas. Certo?"

Sessão 4: o objetivo da sessão foi incrementar o aprendizado da sessão anterior. Foram realizados os mesmos exercícios práticos da fase de treino da sessão 3. A atividade de psicoeducação teve a função de reforçar os conteúdos teóricos sobre controle atencional e controle motor e suas relações com o aprendizado da habilidade de dirigir.

Sessão 5: o objetivo da sessão foi revisar o conceito de atenção focada e desenvolver uma melhor habilidade do controle atencional (visual). A atividade de psicoeducação incluiu a revisão do conteúdo sobre atenção focada e sua importância na habilidade de dirigir. O exercício prático teve como foco estimular a destreza do participante em realizar tarefas de atenção focada em um intervalo de tempo prédeterminado.

Exercícios Práticos: cada participante recebeu uma folha de papel contendo diversos números. A tarefa foi ligar os números que estavam espalhados aleatoriamente em uma folha de papel A4, seguindo a ordem numérica crescente, sem tirar o lápis do papel. Foram realizadas 12 rodadas na fase de treino. A fase de familiarização foi executada com números 1 a 5 para compreensão da atividade e o tempo de execução foi livre.

Após confirmação de que os participantes compreenderam a tarefa, o experimentador explicou que os demais exercícios seriam realizados com limite de tempo e que a quantidade de números aumentaria progressivamente. $\mathrm{O}$ grau de dificuldade aumentou em função do acréscimo de números da sequência e a restrição do tempo para a realização da atividade. O exercício foi realizado duas vezes para cada sequência numérica. As sequências numéricas seguiram as seguintes ordens: 1 a 15, 1 a 30, 1 a 45, 1 a 60 e de 1 a 75. O tempo máximo para a realização de cada exercício foi de 4 minutos, totalizando o máximo de 40 minutos.

Tarefas do Experimentador: o experimentador entregou as folhas para cada participante, conforme a realização de cada exercício. Na fase de familiarização, o experimentador apresentou verbalmente as instruções descritas no item "exercícios práticos" aos participantes. O experimentador entregou, primeiramente, o exercício com 
números de 1 a 5 para familiarização da tarefa. Neste momento, o tempo de execução foi livre.

Após confirmação de que os participantes compreenderam a tarefa, o experimentador explicou que os demais exercícios seriam realizados com limite de tempo e que a quantidade de números aumentaria progressivamente. $\mathrm{O}$ grau de dificuldade aumentou em função do acréscimo de números da sequência e a restrição do tempo para a realização da atividade.

As instruções da tarefa na fase de familiarização serão as seguintes: "Vocês vão receber uma folha de papel contendo uma sequência de números de 1 a 5. A tarefa de vocês será de ligar esses números por linhas, seguindo a ordem crescente (começando do número 1 e terminando no 5). Alguma dúvida? Podem começar."

As instruções da tarefa na fase de treino serão as seguintes: "Agora vocês vão receber várias folhas de papel contendo sequências de números. Eu vou distribuir as folhas uma de cada vez. A tarefa de vocês será de ligar os números por linhas, seguindo a ordem crescente (começando do número 1 até o último número da folha). Você deverá fazer o exercício o mais rápido que puder, sem tirar o lápis do papel. Quando eu falar para parar, vocês deverão parar a atividade da maneira que estiver. Se vocês terminarem antes que eu sinalize, deixem o lápis sobre a mesa e aguardem até todos terminarem para iniciar a próxima folha. A cada folha aumentará a quantidade de números para serem ligados. Eu vou avisar quando começar a próxima folha, ok? Compreenderam? Alguma dúvida? Podemos começar?”

Sessão 6: a sessão teve como objetivo revisar os conceitos de controle motor, habilidade visuo-espacial, atenção visual e atenção auditiva. A atividade de psicoeducação teve a função de incrementar os aprendizados teóricos dos conceitos acima e sua relação com a habilidade de dirigir. O exercício prático teve como função aprimorar o controle motor, habilidade visuo-espacial, atenção visual e atenção auditiva.

Exercício Prático: cada participante ficou dentro de uma das faixas sinalizadas que dividem o chão da sala de treinamento. Os participantes iniciaram as atividades posicionando-se no fundo da sala, dentro de uma das faixas marcadas no chão. Após a apresentação de um sinal auditivo específico (buzina: de caminhão, buzina de carro, freada, sirene de polícia, sirene de ambulância) ou de um sinal visual específico (simulação de um semáforo: verde, amarelo, vermelho), os participantes caminharam em direções determinadas, conforme a seguinte descrição: 


\begin{tabular}{|l|l|}
\hline Pista & Comportamento \\
\hline Som de tráfego & Seguir em frente \\
\hline Buzina de caminhão & Manter-se à esquerda da faixa \\
\hline Buzina de carro & Andar de ré \\
\hline Freada & Parar \\
\hline Sirene & Manter-se à direita da faixa \\
\hline Luz vermelha & Parar \\
\hline Luz amarela & Andar no mesmo lugar \\
\hline Luz verde & Seguir em frente \\
\hline
\end{tabular}

Este exercício incluiu duas etapas: a primeira utilizou somente as pistas sonoras e a segunda, somente as pistas visuais.

Tarefas do experimentador: o experimentador fez marcações no piso da sala de treinamento, estabelecendo divisões com fita crepe de $90 \mathrm{~cm}$ de largura, de forma a criar faixas paralelas, simulando faixas de trânsito. Utilizou as mesmas pistas sonoras das sessões 3 e 4 . O experimentador apresentou, na fase de familiarização, as pistas aos participantes e associando-as a ações específicas (conforme especificado acima). Cada pista foi apresentada por um tempo de 5 segundos. A pista auditiva ambiental de uma rua com tráfego foi apresentada nos tempos de 15 segundos, 25 segundos ou 30 segundos, respeitando a seguinte ordem: tráfego-pista-tráfego-pausa. Foram realizadas 3 rodadas para cada pista, sendo cada rodada de aproximadamente 60 segundos. Houve uma pausa de 60 segundos para mudança da pista a ser apresentada, onde o experimentador demonstrava a associação pista-comportamento. Ao todo foram realizadas 12 rodadas, em um tempo total aproximado de 15 minutos. A ordem de apresentação das pistas foi a seguinte: Buzina de carro, sirene, buzina de caminhão, freada. Houve uma pausa de 5 minutos para descanso e água, antes de iniciar a fase de treino.

$\mathrm{Na}$ fase de treino, as pistas foram apresentadas de forma misturada, seguindo o mesmo padrão de tempo de apresentação dos sons da fase de familiarização. Nesta fase foram realizadas 6 rodadas. Em todas as rodadas foram apresentadas as quatro pistas intercaladas ao som de trânsito, seguindo a seguinte ordem: tráfego-pista-trafego-pistatráfego-pista-tráfego-pista-pausa. Cada pausa foi de aproximadamente 10 segundos. Esta fase teve um tempo aproximado de 20 minutos. 
Para o segundo momento da atividade prática, o experimentador confeccionou um semáforo de madeira contendo as luzes vermelha, amarela e verde. Este foi posicionado próximo ao centro à frente da sala de treinamento. $\mathrm{O}$ experimentador iniciou informando que iria apresentar o som de tráfego e que neste momento, os participantes deveriam caminhar para a frente da faixa. Explicou ainda que durante a apresentação do som de trânsito o semáforo seria acionado e que o participante deveria realizar os movimentos relacionados a cada cor (especificado acima). Quando o som de trânsito se encerrasse, os participantes deveriam retornar para o final da sala para reinício da atividade. O experimentador informou aos participantes que, ao chegarem no início da pista, deveriam dar meia volta e continuar a atividade no sentido oposto e que a luz do semáforo não seria mudada durante o percurso de volta. As pistas visuais foram apresentadas aleatoriamente. Foram realizadas 2 rodadas de familiarização e 8 rodadas de treino, com apresentação do som de trafego variando entre 30 e 45 segundos e tempo total de aproximadamente 6 minutos.

As instruções da tarefa na fase de familiarização foram as seguintes (pistas sonoras): "Cada um de vocês deverá se posicionar no fundo da sala em uma dessas faixas localizadas no chão da sala. A tarefa de vocês será andar para a frente da sala enquanto estiverem ouvindo o som de trânsito. Vamos começar caminhando para a frente e quando vocês chegarem no início da faixa, vocês vão retornar para ofinal da faixa novamente, fazendo o caminho de volta. O som de trânsito será interrompido, primeiramente, por um som de "buzina de carro. Quando vocês ouvirem este som de buzina de carro, vocês deverão andar de ré. Compreenderam? Alguma Dúvida?”

"Agora eu vou inserir um som de sirene alternadamente com o som de trânsito. Enquanto o som de trânsito estiver tocando, vocês deverão andar para a frente da sala.. Quando vocês chegarem no início da faixa, vocês deverão retornar para o final da faixa novamente, fazendo o caminho de volta. O som de trânsito será interrompido por um som de "sirene". Quando vocês ouvirem o som de sirene, vocês deverão manter-se à direita da faixa. Certo? Podemos começar?”.

"Agora eu vou inserir um som de buzina de Caminhão. Quando o som de trânsito for interrompido por um som de "buzina de caminhão, vocês deverão manterse à esquerda da faixa. Certo? Podemos começar?" 
"Agora eu vou inserir um som de freada. Quando o som de trânsito for interrompido por um som de "freada", vocês deverão parar onde estiverem. Certo? Podemos começar?

As instruções da tarefa na fase de treino foram as seguintes (pistas sonoras): “Agora que vocês compreenderam a atividades nós vamos iniciar o treino. Cada um de vocês deverá se posicionar no fundo da sala em uma dessas faixas localizadas no chão da sala. A tarefa de vocês serão andar para a frente da sala enquanto estiverem ouvindo o som de trânsito. Vamos começar caminhando para a frente e quando vocês chegarem no início da faixa, vocês vão retornar para o final da faixa novamente, fazendo o caminho de volta. Quando vocês ouvirem os sons específicos que treinamos (buzina de carro, buzina de caminhão, freada ou sirene) deverão realizar os movimentos os apropriados que foram aprendidos. Vamos recordar quais são? Alguma dúvida? Podemos começar?"

As instruções da tarefa na fase de familiarização foram as seguintes (pistas visuais): "Neste segundo momento, vocês vão caminhar na direção do semáforo enquanto ouvem um som de rua com trânsito. Eu vou ligar o semáforo aqui na frente da sala. A tarefa de vocês será de realizar alguns movimentos com a mudança das cores do sinal.

Quando vocês virem a luz vermelha, terão que parar aonde estiverem. Quando virem a luz amarela, terão que andar no mesmo lugar e quando virem a luz verde, terão que continuar seguindo em frente. Compreenderam?"

As instruções da tarefa na fase de treino foram as seguintes (pistas visuais): “Agora vocês que vocês compreenderam a atividade, nós vamos fazer mais algumas rodadas, tudo bem? Alguma dúvida? Podemos começar?"

Sessão 7: a sessão teve como objetivo revisar o conceito de atenção, especificamente a atenção dividida e aprimorar a habilidade de alternância atencional (visual). A atividade de psicoeducação revisou o conteúdo sobre atenção dividida e sua importância na habilidade de dirigir. O exercício prático teve como foco estimular a destreza do participante em realizar tarefas de atenção dividida em um intervalo de tempo pré-determinado.

Exercícios Práticos:os participantes receberam uma folha de papel contendo números e letras que estavam distribuídos na folha de forma aleatória. A tarefa foi ligar os números às letras do alfabeto seguindo a ordem alfa-numérica crescente (1-A, 2-B, e 
assim sucessivamente), sem tirar o lápis do papel. O tempo máximo de realização de cada sequência foi de 5 minutos.

A fase de familiarização foi realizada com os números 1, 2 e 3 e letras A, B e C. $\mathrm{Na}$ fase de treino foram realizadas 10 rodadas, conforme especificado em "tarefas do experimentador".

Tarefas do Experimentador: entregar as folhas para cada participante, conforme a etapa do procedimento. Na fase de familiarização, o experimentador apresentou verbalmente as instruções descritas no item "exercícios práticos" aos participantes. Realizou a tarefa com uma folha contendo números de 1 a 3 e letras de $\mathrm{A}$ a $\mathrm{C}$, durante um intervalo de tempo livre. Após confirmação de que os participantes compreenderam a tarefa, o experimentador explicou que os demais exercícios seriam realizados com limite de tempo e que a quantidade de números e letras aumentaria progressivamente. $\mathrm{O}$ grau de dificuldade aumentou em função do acréscimo de números da sequência e a permanência do tempo em minutos para a realização da atividade. O exercício foi realizado duas vezes para cada sequência alfa-numérica. As sequencias seguiram as seguintes ordens: De 1-5 e A-E, de 1-10 e A-J, de 1-15 e A-O, de 1-20 e A-T e de 1-26 e A-Z. O tempo máximo para a realização da atividade foi de 5 minutos para cada sequência alfa-numérica .

As instruções da tarefa na fase de familiarização foram as seguintes: "Nesta folha existe números e letras. A tarefa de vocês será de ligar os números às letras por linhas, seguindo a ordem crescente. Comece com o número 1. Ligue este número com uma linha até a letra A. Faça outra linha ligando a letra A até o número 2 e depois do número 2 à letra $B$ e assim por diante, ligando números e letras na ordem crescente até o fim. Compreenderam? Alguma Dúvida?"

As instruções da tarefa na fase de treino foram as seguintes: "Agora vocês vão receber várias folhas de papel contendo sequencias de números e letras. Eu vou distribuir as folhas uma de cada vez. A tarefa de vocês será de ligar os números às letras por linhas, seguindo a ordem crescente (começando do número 1 e ligando este a letra A, depois ligando a letra A até o número 2 e o número 2 até a letra B, fazendo isto até a última letra da folha). Você deverá fazer o exercício o mais rápido que puder, sem tirar o lápis do papel. Quando eu falar para parar, vocês deverão parar a atividade da maneira que estiver. Se vocês terminarem antes de eu falar, deixem o lápis sobre a 
mesa e aguardem até receber a próxima folha que possuíra mais números e letras para serem ligados. Compreenderam? Alguma dúvida? Podemos começar?”

Sessão 8: a sessão incrementou a sessão 6, porém aumentando o grau de dificuldade do treino prático que incluiu a apresentação de ambas as pistas (sonoras e visuais) concomitantemente durante a sessão. O tempo de apresentação das pistas sonoras foram os mesmos da fase de treino da sessão 6. As pistas visuais foram apresentadas de forma aleatória e intercaladas às pistas sonoras.

Sessão 9: a sessão teve como objetivo incrementar o aprendizado da sessão 2. Foram realizados os mesmos exercícios práticos da sessão 2. A atividade de psicoeducação teve a função de reforçar os conteúdos teóricos sobre controle motor e sua relação com a habilidade de dirigir. Após o fim da sessão, o experimentador deixou agendado com cada participante a data do retorno para reaplicação dos testes de avaliação cognitiva. 